\title{
Potencial del Gas de Lutita (Shale gas) en el norte de España en el tránsito a energías con menor huella de carbono
}

\author{
Asier García Pérez ${ }^{(1)}$, Manuel Regueiro(2), Agustín Pieren Vidal(1) \\ (1) Facultad de Ciencias Geológicas. Universidad Complutense de Madrid. C/ José Antonio Nováis, 12, 28040 Madrid, España. \\ asiergp893@gmail.com; apieren@ucm.es \\ (2) Instituto Geológico y Minero de España (IGME). C/ Ríos Rosas, 23, 28003 Madrid, España. \\ m.regueiro@igme.es
}

\begin{abstract}
RESUMEN
El cambio del paradigma energético a fuentes con menor huella de carbono, así como el desarrollo de las tecnologías y técnicas para su extracción, han colocado al gas de lutita en el punto de mira como recurso menos contaminante, abundante en el norte de España, y capaz de suplir en gran medida las necesidades actuales de abastecimiento energético que requiere el país. Sin embargo, existe una importante carencia de información integrada sobre el tema, con respecto a lo geológico, lo económico, lo ambiental y lo social. Como consecuencia de todo ello, se ha desarrollado una fuerte oposición pública que ha paralizado la exploración y la posible explotación de dicho recurso. Los cambios que exige el futuro en la búsqueda de fuentes de energía menos contaminantes y la necesidad de adquirir una posición estratégica en el sector energético, hacen ineludible permitir la investigación y exploración de este recurso en España. Por ello, este trabajo pretende mostrar el panorama actual que rodea al gas natural en un contexto de "tránsito" a energías menos agresivas con el medio ambiente, cómo se realiza su extracción (gas de lutita) y, como debería llevarse a cabo en España con los problemas que ello conllevaría, así como analizar la respuesta y preocupación de la ciudadanía frente a el desarrollo de esta tecnología.
\end{abstract}

Palabras clave: Cuenca Vasco Cantábrica, España, fracturación hidráulica, gas natural, gas de Lutita.

\section{Shale gas potential in the north of Spain in the transition to energies with a lower carbon footprint}

\begin{abstract}
The change to an energy model with lower carbon footprint sources, and the development of the corresponding technologies and extraction techniques has placed shale gas in the spotlight as it is a less polluting resource and it is abundant in the north of Spain. This energy model could be able to supply, to a large extent, the current energy needs of the country. However, there is a relevant lack of information on the subject regarding geological, economic, environmental and social issues. Consequently, a strong public opposition has developed, that has so far paralyzed the exploration and potential exploitation of these resources. The future changes required in the search for less polluting energy sources and the need to acquire a strategic position in the energy sector make it essential to allow both research into this resource and its exploration in Spain. Therefore, this study aims to show the current situation of natural gas in a "transitory" context towards less aggressive energies to the environment as well as to explain how shale gas is produced and how extraction should be carried out in Spain with the problems that this would entail. The study also aims to analyze the citizens' responses and concerns regarding the development of this technology.
\end{abstract}

Keywords: Basque-Cantabrian basin, Spain, hydraulic fracture, natural gas, shale gas. 


\section{Introducción}

Son varias décadas las que tienen que pasar para que la humanidad prescinda definitivamente de la combustión de hidrocarburos para la obtención de energía. Según las estimaciones realizadas por el G8 en su reunión de 2016, esto no sucederá hasta dentro de 70 u 80 años. Pese a varios problemas medioambientales, en los últimos 70 años los hidrocarburos han contribuido activamente a una mejora de la calidad de vida, siendo los que han permitido un aumento de la producción de alimento dedicando menos hectáreas a los cultivos y ganadería pese a una población en constante crecimiento, aportando además fármacos, productos sintéticos y especialmente el suministro energético. En la actualidad se producen anualmente en el mundo para consumo energético 13.200 millones de toneladas equivalentes de petróleo (MTEP) de energía (las TEP son una medida de energía), de las cuáles un $81 \%$ procede del carbón, petróleo y gas. Como consecuencia de su utilización, se emiten $49 \mathrm{GT}$ de $\mathrm{CO}_{2}$ a la atmósfera, y esto es motivo de gran controversia para la opinión pública, debido a su contribución al efecto invernadero y la consecuente influencia en el calentamiento del planeta. Estas cifras muestran lo mucho que debe cambiar el paradigma energético para reducir las emisiones, un cambio que es necesario e inevitable, así como difícil, costoso y lento.

Para llevar a cabo la transición, aparte de ser imprescindibles la energía eólica, solar, nuclear, geotérmica e hídrica, se está alcanzando una electrificación del abastecimiento energético global acompañada de una reducción de hidrocarburos en uso. Por presión política, más que económica, se está sustituyendo poco a poco el carbón, responsable de las mayores emisiones de $\mathrm{CO}_{2}$. Emilio Apud, director de YPF y ex Secretario de Energía y Minería de Argentina, afirma que el gas natural reemplazará al carbón asumiendo un rol protagonista como fuente energética menos contaminante, así como sustituto de los derivados del petróleo empleados para generar energía eléctrica (Energía estratégica en línea).

En el "National Governors Association Summer Meeting" de 2017, el CEO de Tesla Elon Musk, afirmó: "si quieres darle energía a todos los Estados Unidos con paneles solares, no necesitas más que una pequeña esquina que abarque los estados de Nevada, Texas o Utah. Solo hace falta un espacio de alrededor de 100 por 100 millas de paneles solares para alimentar a todo Estados Unidos", agregando que "las baterías que requerimos para almacenar la energía, para asegurarnos de que EEUU tendrá potencia las 24 horas del día, los 7 días de la semana, son de 1 milla cuadrada, en promedio" (El Financiero, en línea). Si bien es cierto que esto representaría todo un avance contra el cambio climático reduciendo aproximadamente el $35 \%$ de las emisiones contaminantes del país, las baterías necesarias para almacenar dicha energía requerirán de cobre, cobalto y litio para su construcción, minerales extraíbles únicamente mediante maquinaria que, de momento, requieren de hidrocarburos para ponerla en movimiento, así como de gas natural para generar la energía eléctrica que deba acumularse en las mismas.

Incluso antes del descubrimiento del gas no convencional, los países occidentales ya dedujeron que, a lo largo de las próximas décadas, el gas natural iba a jugar un papel preponderante en el mix energético. Esto se debe a tres de sus cualidades principales (García Portero, J., 2013):

- Es el combustible fósil más limpio con diferencia, ya que su combustión produce casi exclusivamente $\mathrm{CO}_{2}$ y $\mathrm{H}_{2} \mathrm{O}$, siendo sus emisiones de dióxido de carbono inferiores en un $50 \%$ a las del carbón, y en un $30 \%$ a las del petróleo. Además, estos dos últimos combustibles liberan múltiples subproductos contaminantes de los que el gas natural carece prácticamente en su totalidad.

- Hoy en día, existen mayores reservas extraíbles de gas no convencional que de petróleo. Mientras las reservas extraíbles de petróleo cubrirían los próximos 40 años de consumo mundial, las reservas de gas natural alcanzarían hasta los 60 o 70 años.

- Además, gracias a su amplia distribución geográfica, garantizarían un mayor autoabastecimiento en países fuertemente dependientes de fuentes energéticas externas, tal y como sucede en España, cuya dependencia energética es del 73,3\% (Foro Nuclear 2017).

En España la producción energética total en 2016 ascendió casi a 33 MTEP siendo la contribución más alta, con diferencia, la energía nuclear (15,3 MTEP). Los porcentajes de autoabastecimiento en ese año fueron: $6,6 \%$ en carbón, $0,3 \%$ en petróleo, $0,2 \%$ en gas; del $100 \%$ en energía eléctrica de origen nuclear, hidráulica, eólica, solar y geotérmica; y del $93,6 \%$ en biomasa, biocarburantes y residuos dando un autoabastecimiento energético total del 26,7 \% (Foro Nuclear 2017).

Las próximas décadas estarán acompañadas, nos guste o no, de gas natural, energía nuclear y la obtención y uso de minerales y tecnologías para la nueva generación de baterías. Y un primer paso para alcanzar la participación global es la aceptación social, informando debidamente de lo que esto supone, de 
cómo funciona la tecnología en su explotación y como se llevan a cabo los trabajos de extracción en el territorio. Por ello, antes de empezar a definir los ambientes geológicos y lugares donde abunda este tipo de hidrocarburo, o como funciona esta técnica, debemos preguntarnos primero qué es el gas no convencional y qué tipos de yacimientos existen (GarcíaPérez, A. et al 2018).

\section{¿Qué es el gas no convencional?}

El gas no convencional es exactamente el mismo que el convencional, solo que se extrae mediante métodos, como su propio nombre indica, no convencionales. La ubicación del gas también es distinta de los reservorios geológicos convencionales que se encuentran en rocas de media y alta permeabilidad que requieren de sellos y trampas para retener a los hidrocarburos. Es decir, es aquel gas que se encuentra entrampado en formaciones rocosas de baja permeabilidad en las cuales es por lo tanto necesario crear una permeabilidad artificial con el fin de obtener un flujo de gas (Álvarez, E., y Suárez, C., 2016)

\section{Tipos de gas no convencional}

En la actualidad, se conocen tres tipos principales de gases no convencionales (Figura 1): 1) El "Tight Gas" (gas comprimido/hermético), incluido en rocas sedimentarias (siliciclásticas o carbonáticas) de baja porosidad y permeabilidad, en ocasiones impermeables, cuya recuperación requiere de técnicas que fracturen la roca liberando dicho hidrocarburo; 2) El "Coal

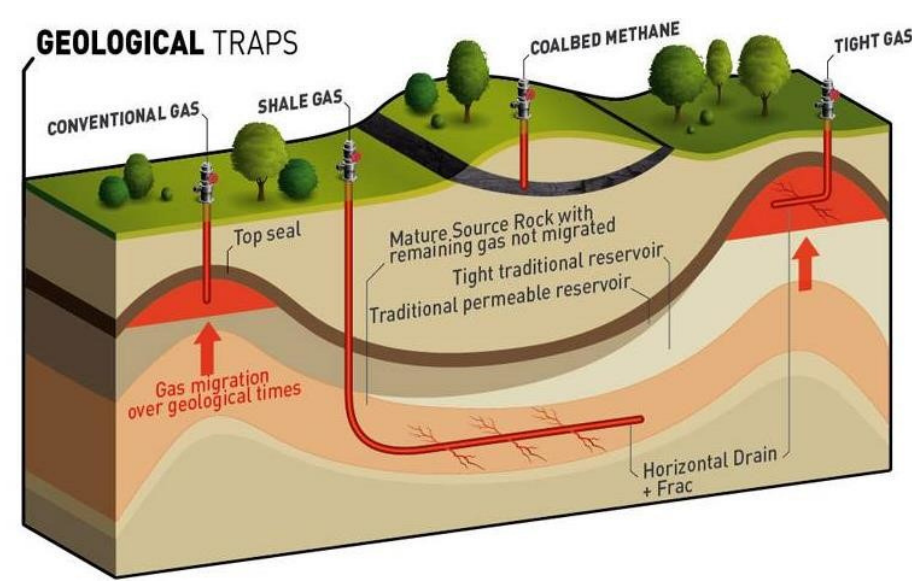

Figura 1. Tipos de Gas no convencional. Fuente: Elzafrany, B., 2016. Figure 1. Types of non-conventional gas. Source: Elzafrany, B., 2016.
Bed Methane" (gas metano de carbón), asociado a capas de carbón, que se extrae de manera similar pero en este caso el gas se encuentra libre o adsorbido en la estructura del carbón; y 3) aquél en el que se centra este trabajo, el "Shale Gas" (gas de lutita o gas de esquisto/pizarra), hidrocarburo (metano, etano, propano o butano) atrapado en la misma roca madre en la que se formó, con una baja porosidad y permeabilidad como pueden ser las rocas clásticas pizarrosas de grano fino, así como lutitas, limolitas o margas organógenas, entre otras (Curbelo, J.L. et al; 2012). La fracturación hidráulica que podría llevarse a cabo actualmente en el Norte de España tiene como objetivo recuperar este último tipo, también llamado "gas pizarra", "gas lutita" o "gas de esquisto".

\section{Formación y distribución del gas no convencional}

Como todo hidrocarburo conocido, su proceso de generación parte de la maduración de materia orgánica (ya sea de origen animal o vegetal) a lo largo de su enterramiento, durante el cual se ve sometida a unas condiciones determinadas de presión y temperatura generando petróleo y gas, para posteriormente quedar conservado en rocas sedimentarias. En función de estas condiciones de presión y temperatura, y del tipo de materia orgánica presente, el yacimiento podrá contener petróleo y/o gas. Para determinar el tipo de hidrocarburo que encontraremos o el potencial generador de las rocas, existen factores indicadores que pueden obtenerse analizando la roca madre del hidrocarburo, como la cristalinidad de la illita, el color de los conodontos, el contenido en volátiles de los carbones, la reflectividad de la vitrinita $\left(R_{0}\right)$, o el Carbono Orgánico Total (TOC) (Álvarez, E. y Suárez, C. 2016). Estos dos últimos son los más utilizados (Figura 2), y son importantes para comprender la caracterización de la materia orgánica como se expone más adelante.

\section{Proceso de evaluación de un proyecto de obtención de gas no convencional}

Ya que EE.UU es el país con más experiencia en la obtención de gas no convencional, basaremos este apartado en las medidas de evaluación que se tomaron en dicho país, ya que sería el procedimiento conveniente a seguir en España.

Para llevar a cabo un proyecto, deben evaluarse los recursos de gas no convencional a nivel de formación y cuenca, a través de una serie de etapas ya establecidas por la US Energy Information 


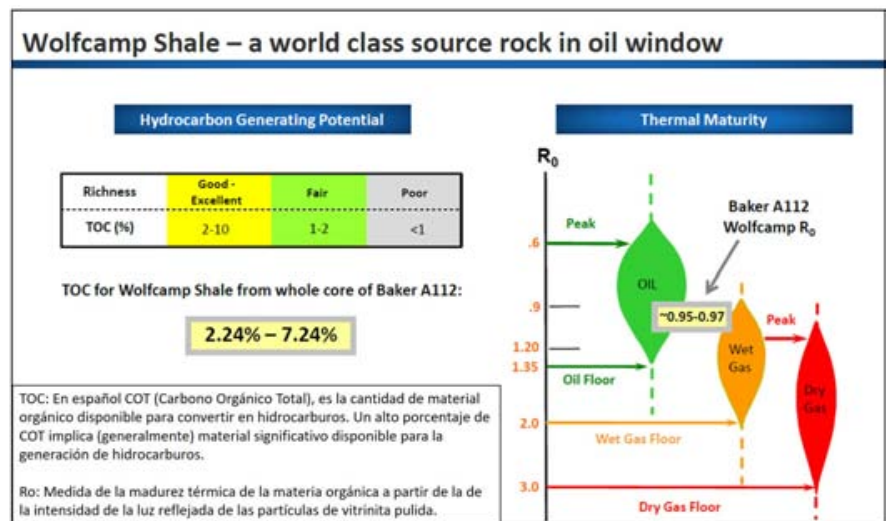

Figura 2. A: Relaciones entre Carbono Orgánico Total (TOC) y el potencial de generación de hidrocarburos. B: tipos de hidrocarburos generados en base a la maduración térmica y la reflectancia de la vitrinita (Ro). Fuente: Modificado de Conferencia de Approaches Resources Wolffork Analyst Day (2010) en Drillinginfo (en línea).

Figure 2. A: Relations between total organic carbon (TOC) and hydrocarbon generation potential. B: Types of hydrocarbons generated based on thermal maturation and the reflectance of vitrinite (Ro). Source: Modified of Conference of Approaches Resources Wolffork Analyst Day (2010) in Drillinginfo (on line).

Administration (EIA), las cuales se resumen a continuación:

En primer lugar, deben definirse las cuencas que alberguen hidrocarburos no convencionales seleccionando las formaciones principales de las mismas a partir de columnas estratigráficas y registros de pozos a partir de sondeos.

Una vez identificadas las formaciones objetivo y realizado un estudio geológico detallado de las mismas, debe definirse el área que las incluya, para posteriormente definir el área prospectiva de cada formación con objeto de esclarecer qué zonas de la cuenca resultarán rentables para la explotación. Para ello se emplean múltiples criterios, como el entorno deposicional, la profundidad del depósito, el TOC, la madurez del crudo y la ubicación geográfica del depósito.

Posteriormente, se determina el GIP, o el volumen total de gas libre y adsorbido contenido en el reservorio (en inglés, Risked Shale Gas-In-Place), que depende de factores como la presión, la temperatura, la porosidad saturada de gas o el espesor neto de roca rica en materia orgánica. Además, debe calcularse también el gas adsorbido por la roca, obteniendo así la concentración de recursos existente en la cuenca.

Por último, se establece el recurso de shale gas técnicamente recuperable (Risked Thecnically Recoverable), multiplicando el gas lutita estimado en la reserva por el factor de eficacia de recuperación de hidrocarburos, que contempla características físicoquímicas como el tipo de mineralogía, la presencia o ausencia de microfracturas, el estado de tensión de la formación, etc.

Por tanto, como puede observarse, el factor clave a la hora de evaluar un proyecto es la existencia de sondeos que permitan identificar la viabilidad técnica, económica y comercial del yacimiento objetivo. (Álvarez, E. y Suárez, C. 2016).

\section{Métodos de exploración}

Para explorar pueden emplearse multitud de técnicas, ya sean geoquímicas, geofísicas, litológicas, cartográficas, estructurales, u otras; con el fin de obtener una estimación de factores como los fluidos presentes, presiones, permeabilidad, porosidad, grado de compactación de la roca o área del depósito, entre muchos otros. Si a través de dichas técnicas el pozo muestra potencial para contener hidrocarburos, se realizan campañas sísmicas con las que se extraen imágenes del subsuelo, es decir, perfiles sísmicos formados mediante el rebote de ondas sonoras en contactos litoestratigráficos mostrando una idea aproxi-

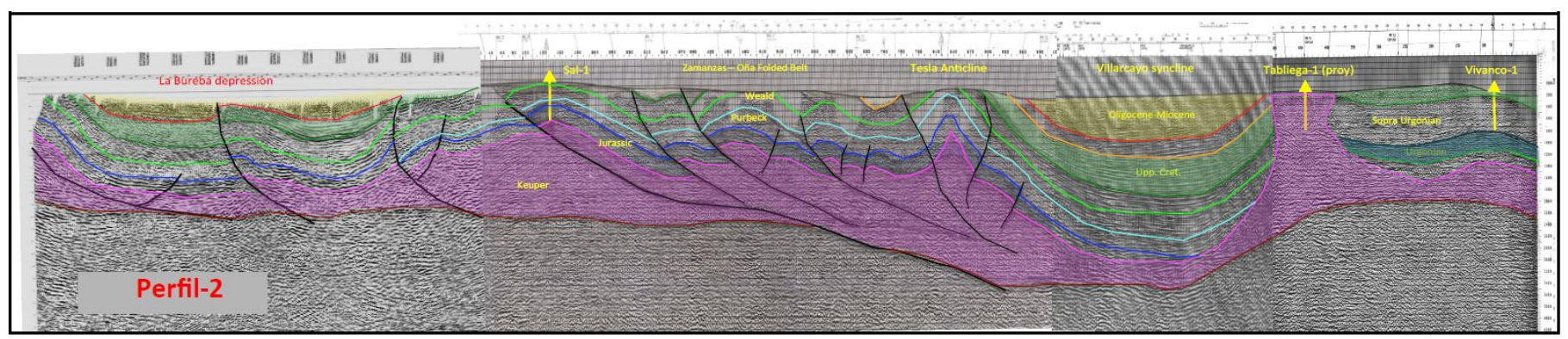

Figura 3. Perfil sísmico de la Cuenca Vasco-Cantábrica con su posible interpretación geológica. Fuente: Cámara, P., 2015.

Figure 3. Seismic profile of the Basque-Cantabrian Basin with its possible geological interpretation. Source: Chamber, P., 2015. 
mada de la morfología y disposición del depósito (Figura 3).

Tras concluir que la zona estudiada puede contener un depósito de hidrocarburos, se emplean pozos de exploración para recopilar información "in situ". De esta forma se puede analizar la roca que forma parte del potencial depósito, y así decidir si se debe proseguir con una exploración más minuciosa para demostrar la existencia de gas. Cuando queda demostrada, se construyen mapas regionales bidimensionales y/o tridimensionales en el caso de que fueran necesarios, ya sean para posteriores exploraciones, reinterpretaciones, estimaciones de reservas o su explotación (Álvarez, E. y Suárez, C. 2016).

\section{Construcción del pozo}

Una vez recopilada toda la información necesaria se elabora el programa de perforación, en el cual se debe establecer el diseño del pozo para que los operarios determinen donde situarlo, cómo llevarlo a cabo y qué secuencia atravesar.

En primer lugar, se debe preparar el terreno donde montar los equipos de perforación, así como los accesos para vehículos y maquinaria. El tamaño del emplazamiento varía en base a ciertos factores como la topografía del terreno, el número de pozos o la naturaleza de las diferentes técnicas a realizar durante la perforación. Debe existir espacio suficiente para el almacenamiento de fluidos y el equipo de fracturación.

Generalmente, durante la fase de exploración los campos de gas lutita ocupan aproximadamente 3 hectáreas de media por pozo construido. No obstante, cuando la construcción del pozo ha finalizado y se procede a la fase de producción, se lleva a cabo una importante restauración del lugar reduciendo el espacio ocupado de forma importante. Se trata de conseguir el aspecto más parecido al inicio de la actuación, tal y como se llevó a cabo en los pozos ilustrados en la Figura 4.

\section{Métodos de extracción}

Como ya se ha comentado, debe crearse una permeabilidad artificial en la capa objetivo, con el fin de que el gas fluya desde la roca en la que se encontraba atrapado y pueda llevarse a cabo su extracción. Para ello existen diversas técnicas, siendo la fracturación hidráulica combinada con la perforación dirigida la más extendida. La perforación dirigida consiste, a grandes rasgos, en realizar una perforación vertical del pozo hasta llegar a la capa donde se alberga el gas y posteriormente desviar el sondeo a lo largo de dicha capa con una inclinación que se aproxime a su pendiente, de forma que se consiga la mayor superficie posible de contacto a lo largo de la misma. La fracturación hidráulica consiste en bombear una mezcla de fluidos a presión compuestos por agua, arena, lodo y productos químicos a través del pozo, con el fin de fracturar la roca (o aumentar la apertura de las fracturas ya existentes), liberando así el gas libre y aquel contenido en los poros de la capa objetivo, generalmente situada a profundidades mayores de los 2500 metros (Figura 5). La mezcla de fluidos que emplea esta técnica consta en un $99.51 \%$ de arena y agua, y el $0.49 \%$ restante lo forman diversos productos químicos cuyo fin sea mantener los canales abiertos, permitiendo un flujo continuado de gas (Álvarez Fernández, I., 2017). Cuando finaliza la extracción es fundamental evitar la contaminación de acuíferos de agua dulce con dicha mezcla, y por ello se extrae del pozo para ser posteriormente tratada y reutilizada. (IGME, 2014).

Además de esto, existen varias técnicas de excitación, o de aumento de dicha permeabilidad:

1) Acidificación, que consiste en estimular la movilidad del hidrocarburo (petróleo o gas) a través de una solución con un ácido reactivo, comúnmente ácido fluorhídrico (HF), con el fin de corroer la roca y aumentar así la permeabilidad de la misma. Puede emplearse de dos formas, acidificando la matriz en formaciones de arenisca, bombeando el ácido a un pozo de bajas presiones con el fin de aumentar el tamaño de los poros naturales y aumentando el flujo de petróleo y gas; o acidificando las fracturas en formaciones de carbonato, bombeando ácidos a un pozo de altas presiones (menores que las empleadas en la fracturación hidráulica) generando una mayor apertura de las mismas y aumentando el flujo de petróleo y gas (Earthworks, en línea).

2) Inyección de gel de propano, una alternativa a la fracturación hidráulica donde se emplea gas licuado de petróleo a base de propano (en inglés, LPG) en lugar de agua, para transportar los productos químicos y la arena necesarios para fracturar la roca. "Dado que el propano se convierte en parte del flujo del yacimiento, la fractura generada se limpia por completo, mientras que, en una estimulación por fractura a base de agua, parte del agua queda atrapada en la fractura", afirma Don LeBlanc, consultor principal de Eastex Petroleum Consultants. Añade también que "una fractura a base de 

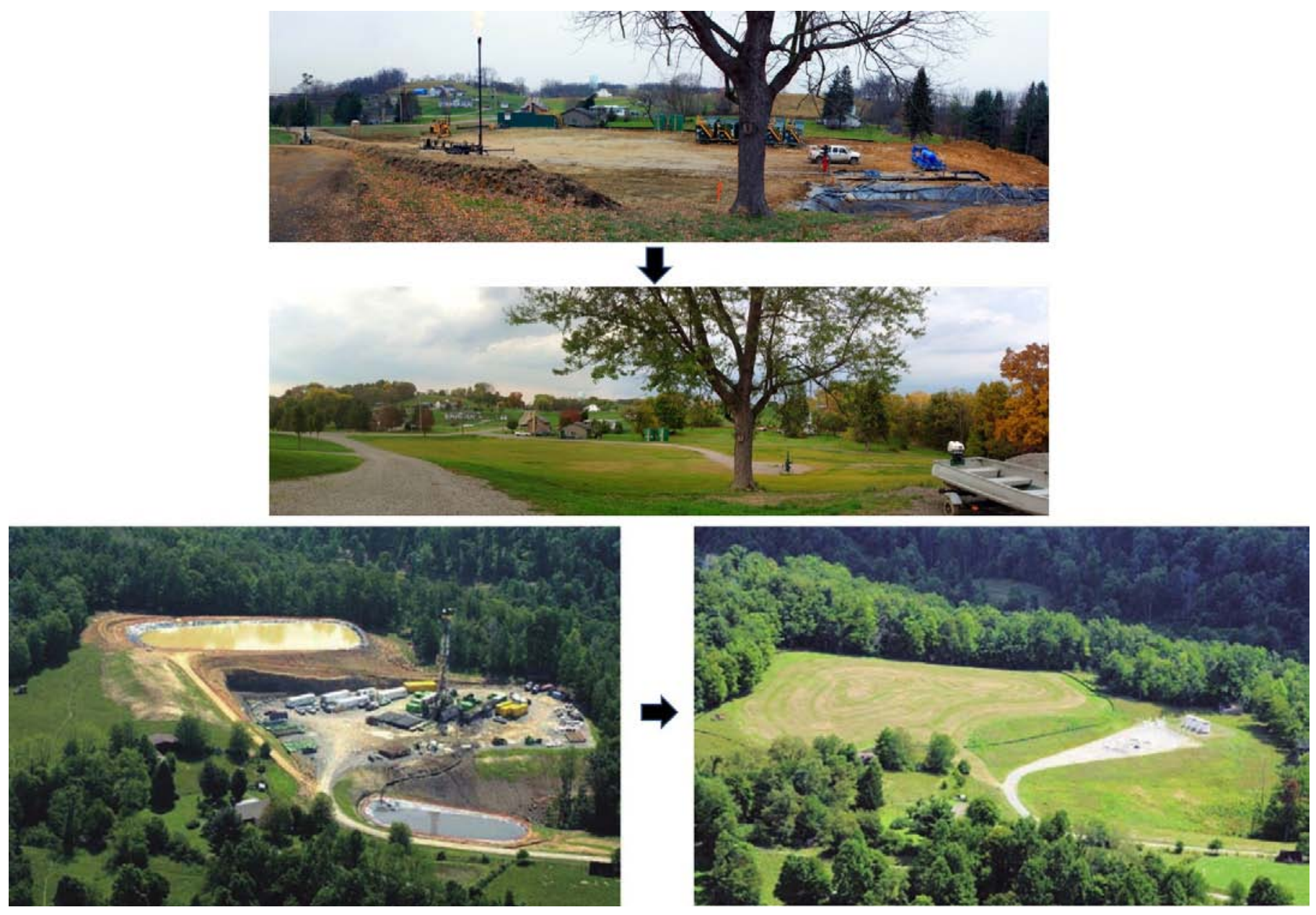

Figura 4. Restauraciones llevadas a cabo en UK y EE.UU, antes y después de la operación. Fuente: Arriba, modificado de Verdon, J.P. (en línea); abajo, modificado de Álvarez, E. and Suárez, C. 2016.

Figure 4. Restoration carried out in UK and USA, before and after the operation. Source: Up, modified by Verdon, J.P. (on line); below, modified by Álvarez, E. and Suárez, C. 2016.

agua tiene una eficiencia de alrededor del 20 por ciento, mientras que el propano tiene un 100 por ciento de eficiencia". No obstante, esta técnica aún se está investigando, y los productores de gas que emplean este método no están revelando datos de sus resultados (Milno, S; en línea).

3) Inyección de $\mathrm{CO}_{2}$. A modo de un segundo sustitutivo del agua de fracturación, también se están realizando ensayos con $\mathrm{CO}_{2}$. Consiste en inyectar a través del pozo de fracturación una forma refrigerada de $\mathrm{CO}_{2}$ a modo de "fluido supercrítico", ni en estado sólido ni líquido (plasma). Sin embargo, es probable que esta técnica no reemplace al agua de fracturación a corto plazo, debido a las limitadas infraestructuras disponibles y los desafíos técnicos que supone (Scheyder, E; en línea).

\section{Situación y perspectivas del gas de lutita en España}

En la actualidad existe una fuerte concienciación sobre el cambio climático, que reclama la necesidad urgente de cambiar nuestro sistema energético para combatirlo, ya sea reduciendo las emisiones de metano y $\mathrm{CO}_{2} \mathrm{O}$ empleando energías renovables. Durante los últimos años, el empleo de energías renovables está en aumento progresivo. Es por esto que debe llevarse a cabo un plan para poder evolucionar progresivamente a una política energética más limpia, tal y como se ha comentado al inicio de este trabajo, haciendo uso de los hidrocarburos ya conocidos.

\section{Evaluación de recursos en España}

A fin de que esto suceda, la Asociación Española de 


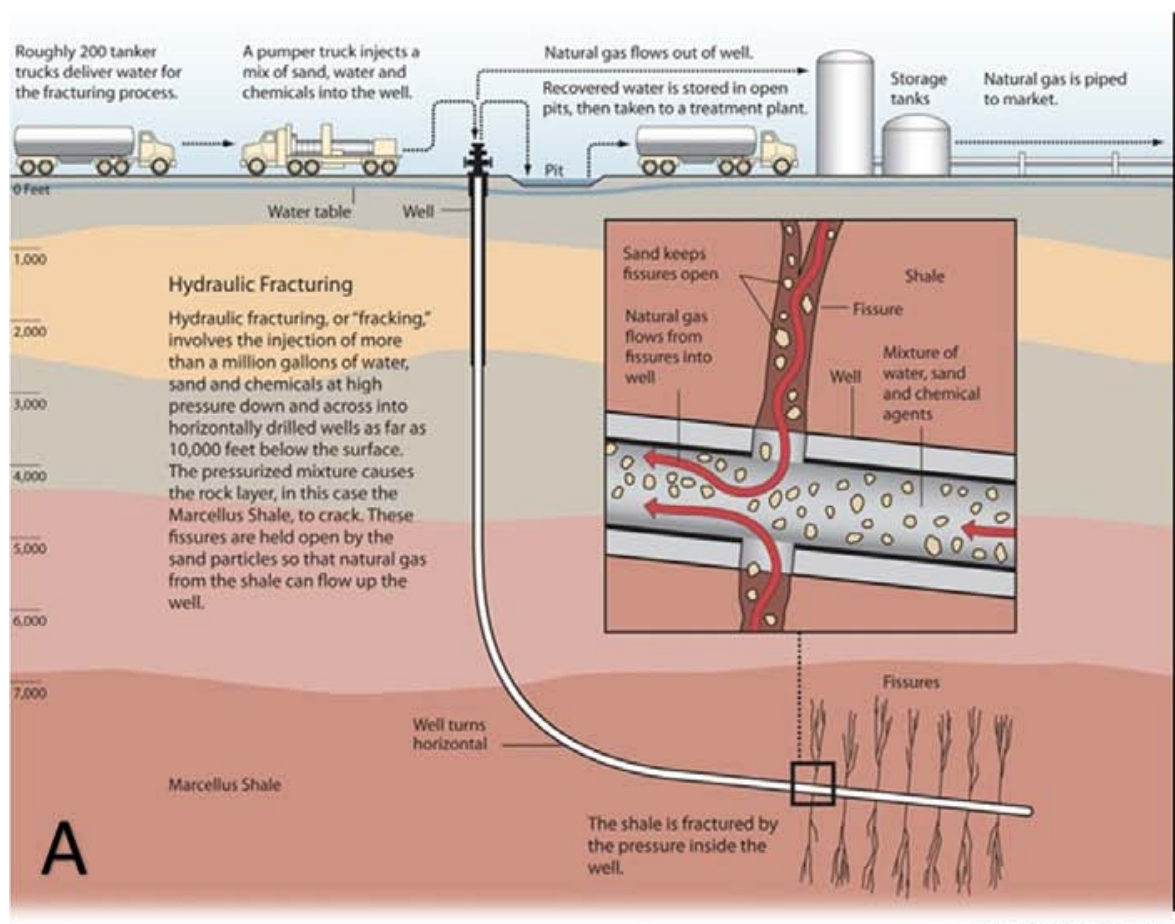

Graphic by Al Granberg

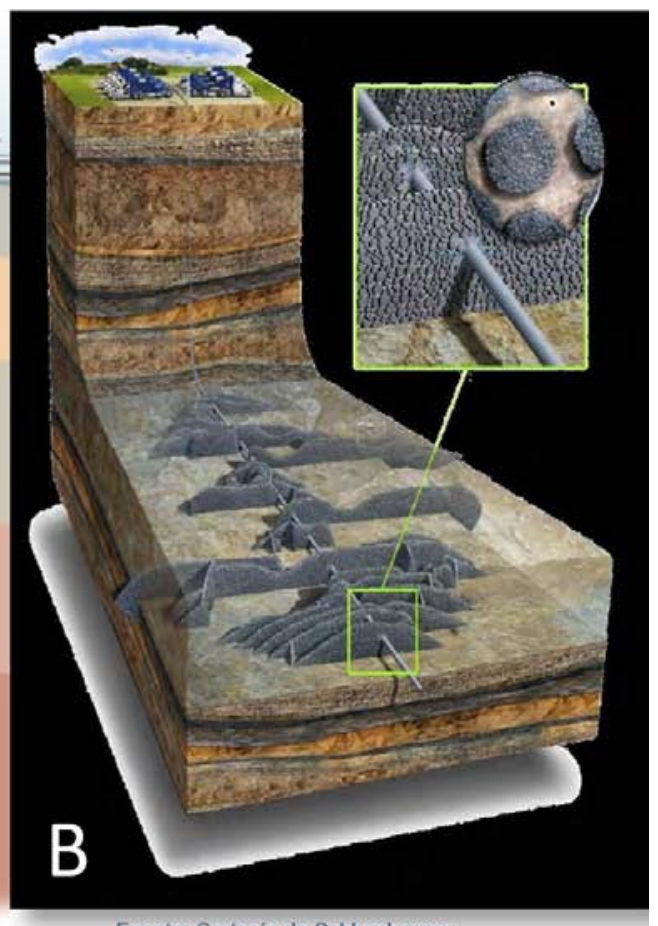

Figura 5. A: Esquema estándar de una instalación de fracturación hidráulica. Gráfico de Al Granberg/ProPublica, fuente: IGME (2014). B: Imagen detallada de la sección cortada por el pozo horizontal, fuente: Álvarez, l., 2015.

Figure 5. A: Standard diagram of a hydraulic fracturing installation. Graphic by Al Granberg / ProPublica, source: IGME (2014). B: Detailed image of the section cut by the horizontal well, source: Álvarez, I., 2015.

Compañías de Investigación, Exploración, Producción y Almacenamiento de Hidrocarburos (ACIEP), realizó en 2013 un estudio sobre la evaluación cuantificada de la previsión de Recursos Prospectivos (R.P.) de Hidrocarburos del subsuelo de España: Petróleo y Gas (Tabla 1).

Según este estudio, España muestra un índice exploratorio bajo en comparación con los países de su entorno europeo, con una estimación media de los recursos de gas no convencional de 2026 BCM (billones de metros cúbicos). Las mayores expectativas se sitúan en la Cordillera Vasco-Cantábrica, donde se podrían encontrar $1086 \mathrm{BCM}$, seguido de la zona Cantábrica del Macizo Hespérico, con 381 BCM, y del área Surpirenaica, con 263 BCM (Tabla 1). Además, el número de perforaciones ha ido en fuerte descenso desde los años 80 y esto ha supuesto una merma en el interés por parte de las empresas extractoras.

$\mathrm{Si}$ se comparan las estimaciones realizadas por GESSAL/ACIEP con los estudios realizados por el Colegio de Ingenieros de Minas del Centro (COIMCE) - la EIA, pueden observarse unas estimaciones menores que la primera (Tabla 2). No obstante, se debe tener en cuenta las bases de cada cálculo, ya que GESSAL/ACIEP analizó las formaciones poten- cialmente productivas en varias zonas de España, el COIMCE analizó las zonas de mayor probabilidad de encontrar los reservorios y la EIA únicamente analizó lutitas jurásicas del Lías, una formación de la cuenca Vasco-Cantábrica (GESSAL, 2013; y US DPT OF ENERGY, 2015).

Con un mayor número de perforaciones podrían verificarse dichas estimaciones, así como encontrar pozos positivos en regiones ya aceptadas como negativas, tal y como sucedió en el caso de Viura, pozo de gas convencional descubierto entre dos antiguos sondeos negativos separados unos $12 \mathrm{~km}$ (Rioja 4 y Rioja 5), dando a entender que una red de exploración más densa aumentaría el potencial del territorio español (GESSAL, 2013).

\section{Situación actual en Estados Unidos y Europa en rela- ción con España}

En la actualidad, EEUU se sitúa en cabeza con respecto a la explotación de hidrocarburos no convencionales, y a éste le siguen otros países como Australia y Argentina, en los que se están produciendo grandes avances. 


\begin{tabular}{|c|c|c|c|c|}
\hline Dominio Geológico & $\begin{array}{c}\text { Shale Gas } \\
(\mathbf{B C M})^{*}\end{array}$ & $\begin{array}{c}\text { Tight Gas } \\
(\mathbf{B C M})^{*}\end{array}$ & $\begin{array}{c}\text { Coal Bed } \\
(\mathbf{B C M})^{*}\end{array}$ & $\begin{array}{c}\text { Total } \\
(\mathbf{B C M})^{*}\end{array}$ \\
\hline $\begin{array}{c}\text { Cuenca Vasco } \\
\text { Cantábrica }\end{array}$ & 1.084 & 2 & $\mathrm{x}$ & 1.086 \\
\hline Pirineos & 260 & 3 & $\mathrm{x}$ & 263 \\
\hline Cuenca del Duero & 72 & $\mathrm{x}$ & $\mathrm{x}$ & 72 \\
\hline Cuenca del Ebro & 32 & 1 & $\mathrm{x}$ & 33 \\
\hline Cordillera Ibérica & 95 & $\mathrm{x}$ & $\mathrm{x}$ & 95 \\
\hline Cadenas Catalanas & 15 & $\mathrm{x}$ & $\mathrm{x}$ & 15 \\
\hline $\begin{array}{c}\text { Cuenca del } \\
\text { Guadalquivir }\end{array}$ & 79 & 2 & $\mathrm{x}$ & 79 \\
\hline Cuenca Bética & $\mathrm{x}$ & $\mathrm{x}$ & $41,3^{* *}$ & 381 \\
\hline Macizo Hespérico & 340 & $\mathbf{7}$ & $\mathbf{4 1}$ & $\mathbf{2 . 0 2 6}$ \\
\hline Totales: & 1.977 & & & 2 \\
\hline
\end{tabular}

Tabla 1. Resumen de recursos prospectivos de hidrocarburos "no convencionales" de España en billones de metros cúbicos de gas (BCM). Fuente: IGME 2014, en GESSAL, 2013.

Table 1. Summary of prospective resources of "unconventional" hydrocarbons in Spain in billions of cubic metres of gas (BCM). Source: IGME 2014, in GESSAL, 2013.

\begin{tabular}{|c|c|c|c|c|c|}
\hline Título del Informe & Fuente & Fecha & \multicolumn{2}{|l|}{ RECURSOS PROSPECTIVOS } & DURACIÓN \\
\cline { 4 - 5 } & BCM & TCF & Años \\
\hline $\begin{array}{c}\text { EVALUACIÓN PRELIMINAR DE LOS RECURSOS } \\
\text { PROSPECTIVOS DE HIDROCARBUROS } \\
\text { CONVENCIONALES Y NO CONVENCIONALES EN } \\
\text { ESPAÑA }\end{array}$ & Gessal Aciep & mar-13 & 1.978 & 69,8 & 58,2 \\
\hline $\begin{array}{c}\text { EXTRAPOLACIÓN A ESPAÑA DE LOS RECURSOS } \\
\text { EXPLORATORIOS DE SHALE GAS EXISTENTES EN } \\
\text { LOS EEUU }\end{array}$ & $\begin{array}{c}\text { Ingenieros de Minas } \\
\text { del Centro (COIMCE) }\end{array}$ & feb-13 & 1.339 & 47,3 & 39,0 \\
\hline $\begin{array}{c}\text { Technically Recoverable Shale Oil and Shale Gas } \\
\text { Resources: An Assessment of 137 Shale } \\
\text { Formations in 41 Countries Outside the United } \\
\text { States }\end{array}$ & $\begin{array}{c}\text { U.S. Energy } \\
\text { Information } \\
\text { Administration (EIA) }\end{array}$ & jun-13 & 226 & 8,0 & 6,7 \\
\hline
\end{tabular}

Tabla 2. Diferentes estudios de evaluación preliminar de recursos de hidrocarburos no convencionales en el año 2013 , tanto en billones de metros cúbicos de gas natural (BCM) como en trillones de pies cúbicos de gas natural (TCF). Fuente: Consejo Superior de Colegios de Ingenieros de minas (2013), en Arenillas, A. (2014).

Table 2. Different preliminary evaluation studies of unconventional hydrocarbon resources in 2013, both in billions of cubic metres of natural gas (BCM) and in trillions of cubic feet of natural gas (TCF). Source: Higher Council of Engineers of Mines (2013), in Arenillas, A. (2014).

Echando la vista atrás en Estados Unidos, se puede observar un rápido avance en el país durante el desarrollo de esta técnica, a partir de la escasez de gas natural que tuvo lugar durante los años 70 . Dicha escasez impulsó las políticas referentes al gas natural o convencional. Durante los años 60 y 70 se regularon los precios máximos a niveles por debajo del límite de equilibrio, dando como resultado mucha demanda y poca oferta, con una importante reducción de producción y reservas. En la Figura 6 se puede observar 


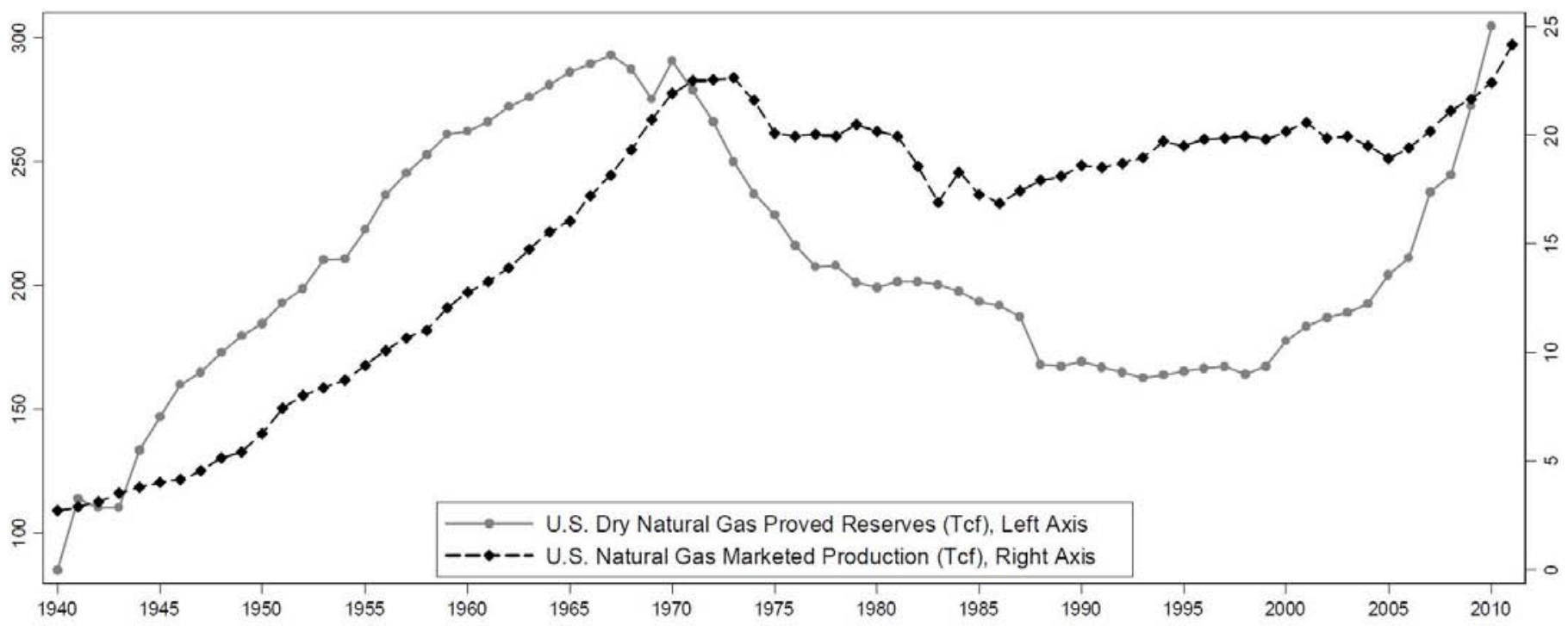

Figura 6. Reservas de gas natural de Estados Unidos y producción comercializada. Fuente: Energy Information Administration, natural gas data, en Wang, Z. and Krupnick, A. (2013).

Figure 6. United States natural gas reserves and commercialized production. Source: Energy Information Administration, natural gas data, in Wang, Z. and Krupnick, A. (2013).

toda la evolución de las reservas y producción en Estados Unidos desde 1940 hasta 2010, mostrando así un pico máximo de reserva en 1978, y una tendencia a la baja en producción a lo largo de los años setenta (Wang and Krupnick, 2013).

Esta profunda escasez de gas natural condujo a la aprobación de la Ley de Gas Natural de 1978 por la cual se requería la retirada gradual de los controles de precio de la cabeza de pozo y proporcionó incentivos en los precios para desarrollar nuevo gas natural, tanto convencional como no convencional. Fue entonces cuando la Comisión Federal de Energía, la Administración de Investigación y Desarrollo de la Energía (ERDA) y el Departamento de Energía de Estados Unidos (DOE) fomentaron los esfuerzos por extraer gas no convencional ya que la base de este recurso podría ser muy grande, de acuerdo con los estudios realizados por la Oficina de Minas de los EE.UU. Por otro lado, los programas de I+D, patrocinados por el gobierno ayudaron con las innovaciones tecnológicas y las políticas fiscales. Los créditos blandos, ofrecieron a las empresas motivos para extraer gas lutita, y establecieron la capacidad de arrendar los derechos de tierras y minerales obteniendo importantes beneficios económicos, lo cual incentivó la aceptación pública al progreso del gas no convencional. No obstante, la situación de Estados Unidos con respecto a las políticas de derechos de tierras y minerales (a través de la cuales los propietarios del terreno donde se encuentre el petróleo, gas o carbón, puedan arrendar sus derechos mineros a empresas de extracción (Confuzal, en línea), difiere de otros países, en donde dichos derechos son propiedad del Estado (Wang Z. and Krupnick, A. 2013).

Una de las causas del éxito de la fracturación hidráulica en Estados Unidos fue gracias a su geología, al existir una cantidad ingente de recursos abundantes en su territorio. El país dispone de una roca madre por lo general de muy buena calidad, con altos porcentajes de materia orgánica y en unas condiciones de presión y temperatura idóneas para la maduración de ésta, en ventana de petróleo y gas (Álvarez y Suárez, 2016).

A lo largo de los últimos años, la situación energética en EEUU se ha revertido gracias a un aumento en su producción de gas y petróleo procedentes de pizarras y areniscas de baja permeabilidad, convirtiéndose de manera progresiva en un país cada vez más autosuficiente en hidrocarburos. La explotación de hidrocarburos no convencionales ha permitido a EEUU disponer de importantes cantidades de gas, a un coste únicamente del $20 \%$ del precio que se paga en el mercado europeo, además de impulsar la economía y generar casi dos millones de empleos, con la consiguiente entrada de capital de las arcas públicas y reducción del déficit externo (Cámara Rascón, $A$. and Pendas Fernández, F; 2013).

En Europa, por el contrario, el progreso en cuanto a fracturación hidráulica y perforación horizontal llegó más tarde. No se produjeron aplicaciones prác- 
ticas hasta la década de los 80 , cuando la telemetría de fondo de pozo hizo a esta tecnología comercialmente viable. Entre 1980 y 1983, la compañía Elf Aquitane realizó con éxito las primeras pruebas de perforación horizontal, y ya en los años 90, en Alemania se combinaron los procesos de fracturación junto con los de perforación horizontal a 5000 metros de profundidad. En la actualidad, ya se han realizado numerosos estudios geológicos de gas de lutita y la evaluación de reservas aún se encuentra en fase inicial, con más de un millar de pozos horizontales y fracturaciones hidráulicas realizadas. Polonia y Reino Unido son los países más avanzados respecto a la investigación de este recurso.

España se encuentra en la fase preliminar en cuanto a prospección de hidrocarburos no convencionales se refiere, y para desarrollarla sería necesario el cumplimiento de la vigente Ley de Hidrocarburos, así como la colaboración de organismos públicos, empresas y universidades. La Asociación Española de Compañías para Exploración y Producción de Hidrocarburos y Almacenamiento Subterráneo (ACIEP) defiende a la Cuenca Vasco-Cantábrica como el área de mayor potencial de recursos no convencionales que encontramos en la península, sin embargo, aún son necesarios muchos avances en exploración para realizar una correcta estimación de reservas.

Por otra parte, debido al fuerte rechazo social y a los bajos precios del gas, muchas empresas están renunciando a la extracción de gas mediante fracturación hidráulica en el país, principalmente en el Norte. Diversos grupos conservacionistas (popular- mente conocidos como "ecologistas") calaron hondo en la forma de pensar de la gente exponiendo los problemas medioambientales que ello podía generar, y mientras el Partido Popular cambió la normativa estatal para llevarlo a cabo a partir de 2013, varias comunidades como la del País Vasco o Cantabria apoyaron las leyes autonómicas "antifracking". Ya en marzo de 2016, en el Congreso se llevó a cabo una iniciativa instando al Gobierno a prohibir la técnica, y fue entonces cuando empresas como BNK, la canadiense R2 Energy, la norteamericana San León y la Sociedad de Hidrocarburos de Euskadi SHESA, renunciaron ya a esta técnica, a fin de que no corrieran los plazos de tramitación y no perder los derechos de investigación que ya se les habían concedido (Planelles, M; en línea).

\section{Demanda y producción}

Durante los últimos años, el empleo de gas natural como energía primaria ha aumentado considerablemente, así como la producción del mismo. Dicha tendencia ha ido en aumento y se prevé que siga haciéndolo situándose como la energía primaria con mayor tasa de crecimiento. Muchos sectores han recurrido ya a utilizar distintas energías en base a las nuevas políticas, entre las cuales se ha observado un mayor empleo del gas natural. Según la previsión de producción de gas natural que se observa en la Figura 7, ésta irá en aumento hasta el año 2035, y será en EEUU, seguido de Canadá y China, donde se observe

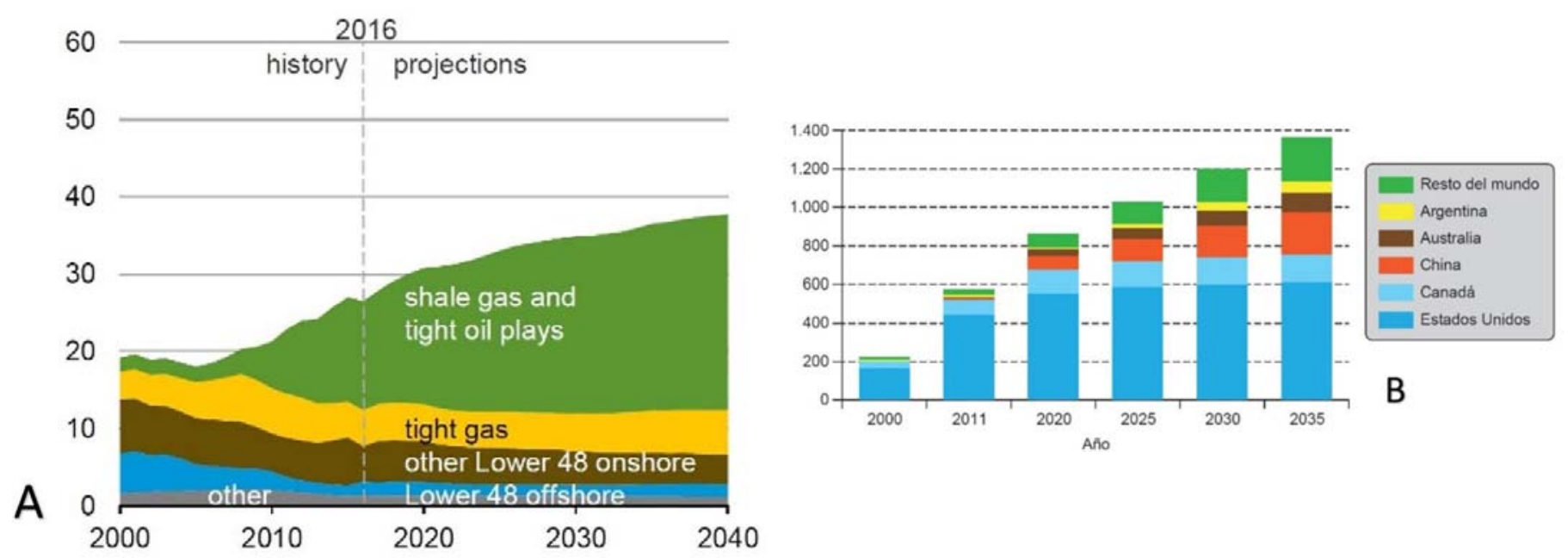

Figura 7. Producción de gas natural en EE.UU (A) y principales países productores (B). Fuentes: Sieminski, A., 2017; y Álvarez, E., and C. Suárez, 2016.

Figure 7. Natural gas production in the USA (A) and main producing countries (B). Sources: Sieminski, A., 2017; and Álvarez, E., and C. Suárez, 2016. 
el mayor crecimiento del gas natural no convencional en los años venideros.

La Agencia Internacional de Energía (EIA) afirma que, ya en 2017 , el gas natural suministró el $22 \%$ de la energía utilizada en todo el mundo, constituyendo casi una cuarta parte de la generación de electricidad y un importante papel como materia prima en la industria. Agrega también, que la demanda mundial de gas a comienzos de este siglo muestra un importante crecimiento hasta el año 2022.

La demanda de gas en Europa fue gravemente afectada por la crisis económica, pero prosiguió en aumento hasta el año 2010, donde se comenzó a observar una tendencia decreciente. En cambio, de cara al futuro, se prevé un crecimiento moderado de la demanda, estimando un aumento del $0.6 \%$ anual (Álvarez, E., and C. Suárez, 2016). Según el estudio realizado por Michael Schuetz (2011), la demanda de gas en Europa aumentará hasta un $82.8 \%$ en 2030 (Fuente: Regueiro, M. 2016).

En España, la dependencia de las importaciones de gas es absoluta (99.8\%). El suministro de gas está muy diversificado, siendo sus mayores proveedores Argelia, Nigeria, Abu Dhabi, Catar y Omán, alcanzando un número de 11 países proveedores en 2014. Cabe decir que, en 2013, España fue el primer consumidor europeo de GNL (Gas Natural Licuado) y el quinto en importaciones de GNL en el mundo (Álvarez, E., and C. Suárez, 2016).

El Instituto Nacional de Estadística, estimó un consumo de gas de $24.590 \mathrm{ktep}$ (miles de toneladas equivalentes de petróleo) en 2015, con una producción del mismo inferior al $0.9 \%$ (Figura 8 ). Además, cabe añadir que la factura por los hidrocarburos es aproxima- damente igual a los ingresos que se obtienen por turismo, aproximadamente un $4,5 \%$ del PIB, 54.000 millones de $€$ laño (Regueiro, M., 2016).

\section{Recursos y reservas mundiales}

El volumen mundial de reservas probadas de gas (Fig. 9) se estima en $187 \mathrm{tcm}$ (trillones de metros cúbicos). Los recursos técnicamente recuperables ascienden a $810 \mathrm{tcm}$, correspondiendo a $343 \mathrm{tcm}$ de recursos no convencionales (dentro de los cuales, $212 \mathrm{tcm}$ proceden de gas lutita) y $467 \mathrm{tcm}$ a recursos convencionales. Dichos recursos equivalen a 235 años de producción, considerando el actual nivel de producción anual (Álvarez, E., and C. Suárez, 2016).

Al incluir la prospección de gas lutita, las reservas no convencionales de EEUU despertaron interés, ya que incrementaron sus estimaciones de reservas de gas no probadas en un $45 \%$, pasando de 32.7 a $47.4 \mathrm{tcm}$.

En Europa, la IEA estima que podrían existir trillones de metros cúbicos repartidos por varios estados miembros, aunque aún existe mucha incertidumbre respecto al emplazamiento, tamaño o viabilidad comercial de las reservas (Figura 10). Se han llevado a cabo actividades exploratorias en Reino Unido, Suecia, Polonia, Alemania, Rumanía y Dinamarca (Estefanell Alós, J., 2014). Del mismo modo, en España se estiman grandes cantidades de este recurso, pero apenas se han llevado a cabo investigaciones de gas no convencional en el país (se han realizado menos de 5 sondeos cada $1000 \mathrm{~km}^{2}$ estando estos además dirigidos a la exploración de hidrocarburos convencionales).



Fuente: $\mathrm{M}^{\circ}$ de Energía, Turismo y Agenda Digital
B

\begin{tabular}{|c|c|c|c|c|}
\hline & Consume & & & \\
\hline & ktep* & $\%$ & Variación intera & anual \% \\
\hline Total & 123.868 & 100,0 & & 4,6 \\
\hline Petróleo & 52.434 & 42,3 & & 3,9 \\
\hline Gas natural & 24.590 & 19,9 & & 3,9 \\
\hline Nuclear & 14.927 & 12,1 & & 0 \\
\hline Carbón & 14.426 & 11,6 & & 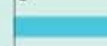 \\
\hline Eólica, solar y geotérmica & 7.476 & 6,0 & $-1,6$ & \\
\hline Biomasa, biocarburantes & & & & \\
\hline y residuos renovables & 7.371 & 6,0 & & 8,0 \\
\hline Hidráulica & 2.397 & 1,9 & $-28,9$ & 政 \\
\hline Residuos no renovables & 260 & 0,2 & & 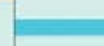 \\
\hline Saldo imp-exp electricidad & -13 & & & \\
\hline
\end{tabular}

*ktep: miles de toneladas equivalentes de petróleo
Fuente: Ministerio de Energía, Turismo y Agenda Digita

Figura 8. Produccion interior de energía primaria (A) y consumo de energía primaria en el año 2015 (B). Fuente: Izquierdo Llanes, G., 2017. Figure 8. Domestic production of primary energy (A) and primary energy consumption in 2015 (B). Source: Izquierdo Llanes, G., 2017. 


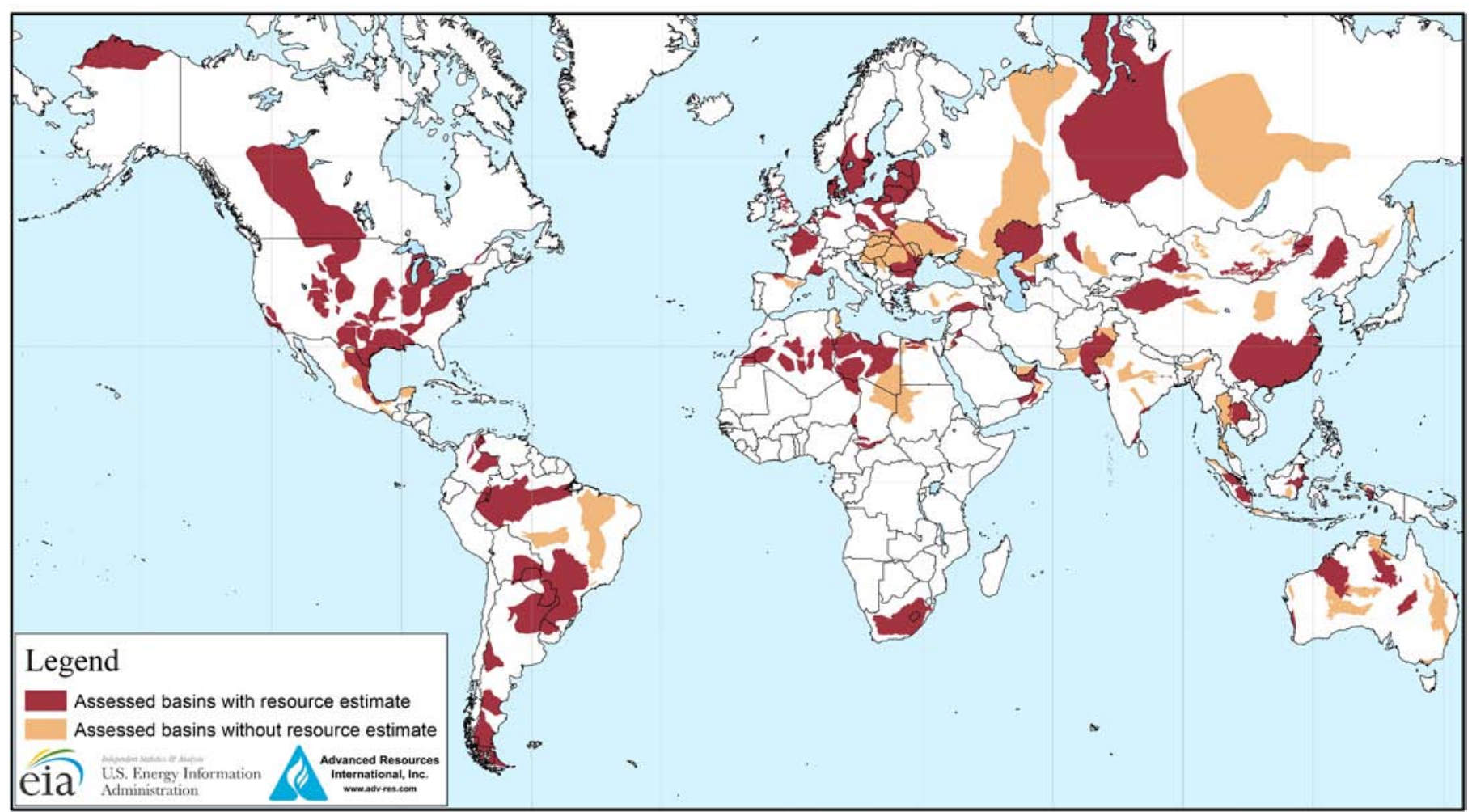

Figura 9. Principales cuencas con formaciones estimadas de petróleo y gas lutita en el año 2013. Fuente: US Energy Information Administration, en U.S Energy Information Administration, Analysis \& projections (en línea).

Figure 9. Main watersheds with estimated oil and shale gas formations in 2013. Source: US Energy Information Administration, in U.S Energy Information Administration, Analysis \& projections (on line).

\section{Precios y empleo}

Debido al aumento de la producción de gas de lutita en EEUU, los precios del gas han ido disminuyendo progresivamente. Durante los años 2005 y 2012, dicho país redujo el precio del gas natural de 12 a 3US\$/millón de BTU (British Thermal Units, medida de energía empleada con frecuencia para expresar los precios del gas natural; $1000 \mathrm{BTU}=0,293 \mathrm{kWh}$ ), mientras que en Europa, según los estudios realizados por la Independent Chemical Information Service (ICIS), durante el mismo periodo de tiempo el precio del gas se incrementó en un $83 \%$, situándonos entre los 9 y 10 US\$/millón de BTU. En la actualidad, los precios del gas se encuentran en torno a los 3.15 US\$/millón de BTU (Figura 11).

En el mercado español los precios del gas están principalmente vinculados a los precios del petróleo. Con la competencia del mercado del gas, es probable que el precio del petróleo descienda, y las importaciones y reexportaciones de GNL favorezcan a los precios finales del mercado spot, precio por el que está influido el GNL español. Sin lugar a dudas, la producción nacional puede satisfacer la demanda creando un mercado más dinámico, y sería capaz de atenuar el déficit comercial de gas en España (Álvarez, E., and C. Suárez, 2016).

\section{Litologías potenciales en el norte de España}

España es un país poco explorado en lo que se refiere al tema de hidrocarburos. Contiene áreas sin estudiar, ambientes de deposición propicios e historiales de enterramiento y regímenes de presión análogos a otros países donde se han desarrollado proyectos de explotación de gas lutita (Arenillas, A., 2014). No obstante, debido al gran éxito del gas de lutita en EE.UU y en países europeos como Polonia o Reino Unido, se comenzó a investigar el potencial extractivo de este gas en nuestro país, revelando así numerosos yacimientos con cantidades potencialmente económicas en el Norte de la península.

El estudio realizado por GESSAL (2013), ya comentado con anterioridad, dividió el territorio español en diversos dominios basándose en criterios geológicos y geográficos con sus respectivas estimaciones en recursos prospectivos de hidrocarburos no conven- 


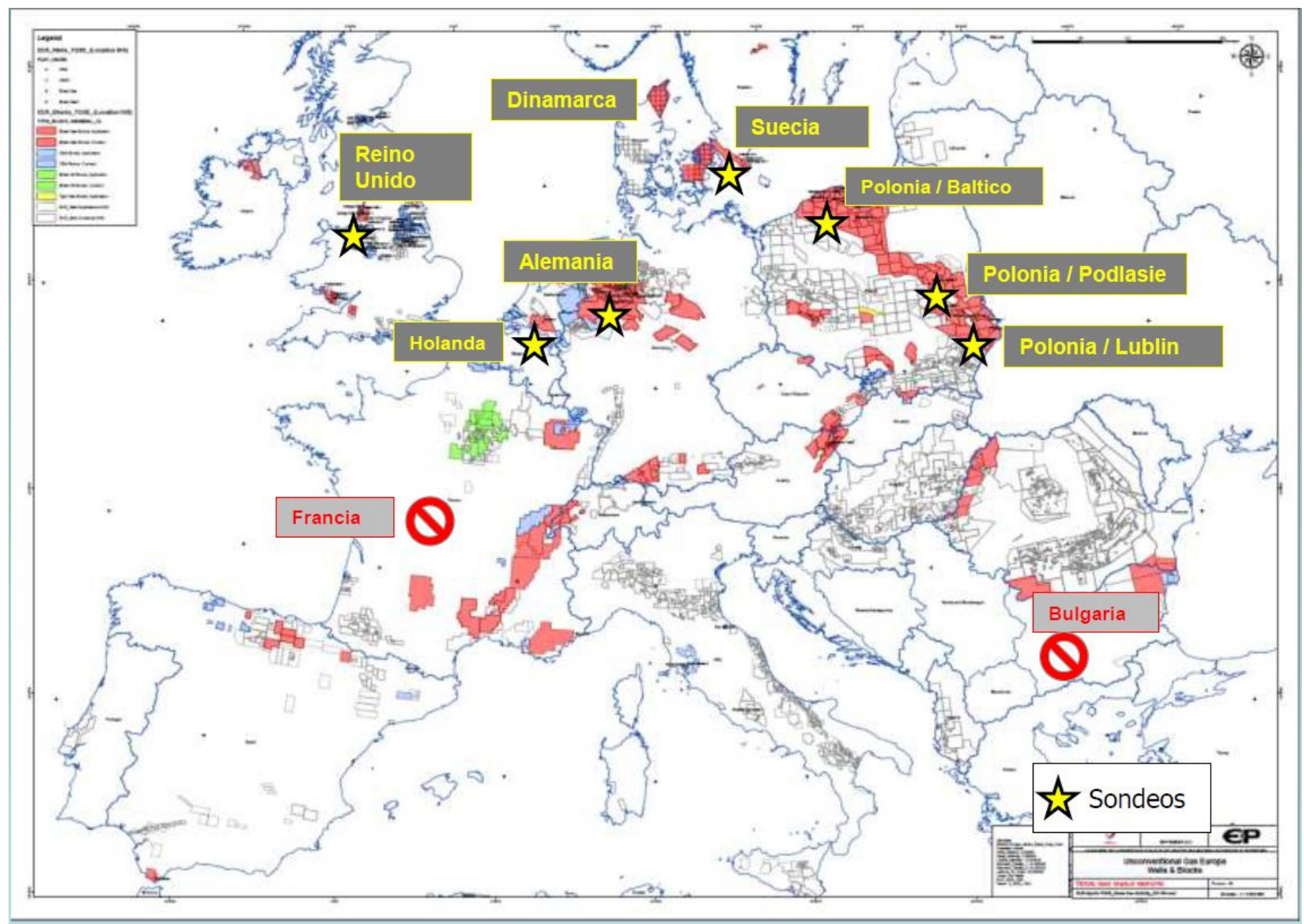

Figura 10. Sondeos de exploración realizados en distintos estados miembros de las Unión Europea. Se ha marcado con una señal de prohibición, aquellos estados donde la técnica de fracturación hidráulica no está actualmente permitida. Fuente: Regueiro, M., 2016.

Figure 10. Exploration surveys carried out in different member states of the European Union. Those states where the technique of hydraulic fracturing is not currently allowed have been marked with a prohibition sign. Source: Regueiro, M., 2016.

cionales. De esta forma se dedujo que las mayores cantidades potenciales de gas no convencional se encuentran en la zona norte de la península, destacando la Cuenca Vasco-Cantábrica y el norte cántabro del Macizo Hespérico, regiones en las que se centra este artículo (Figura 12).

\section{Cuenca Vasco-Cantábrica}

Con una superficie aproximada de $22.000 \mathrm{~km}^{2}$, ya cuenta con información procedente de 202 sondeos de exploración perforados y está considerada la mayor zona de interés de la península en los informes nacionales (GESSAL, 2013) e incluida en los balances internacionales de este recurso (ARI 2013).
La Cuenca Vasco-Cantábrica engloba una secuencia de formaciones que contienen arcillas ricas en materia orgánica de edad Ordovícico, Silúrico, Jurásico y Cretácico (Figura 13). De todas ellas, las lutitas jurásicas (Lías) parecen ofrecer el mayor potencial. Las margas y lutitas del Jurásico muestran unos valores TOC entre el 2 y el $4 \%$, mientras que la reflectancia de la vitrinita (Ro) revela valores entre el 1,1 y 1,2 ; mostrando, por ello, un potencial de generación de hidrocarburos de muy bueno a excelente. Con respecto a los análisis realizados en lutitas (ortopizarras) ordovícico-silúricas infrayacentes, evidencian potenciales muy pobres en gas lutita. En rocas Cretácicas, por otra parte, apenas existen estudios de evaluación, a excepción de los realizados por la empresa San Leon Energy, indicando un promedio 
A

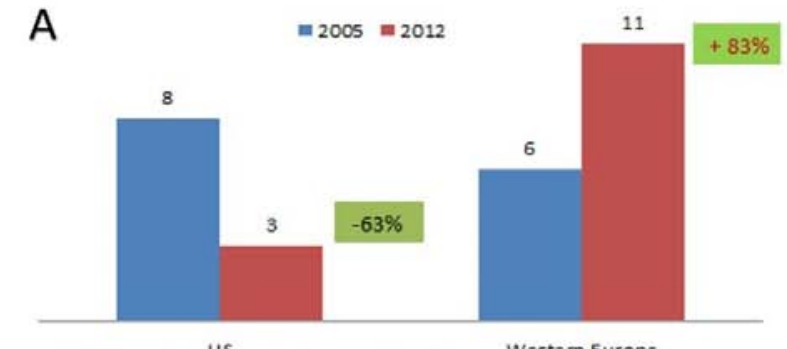

Source: ICIS Heren Europen Gas Markets and Cefic Analysis

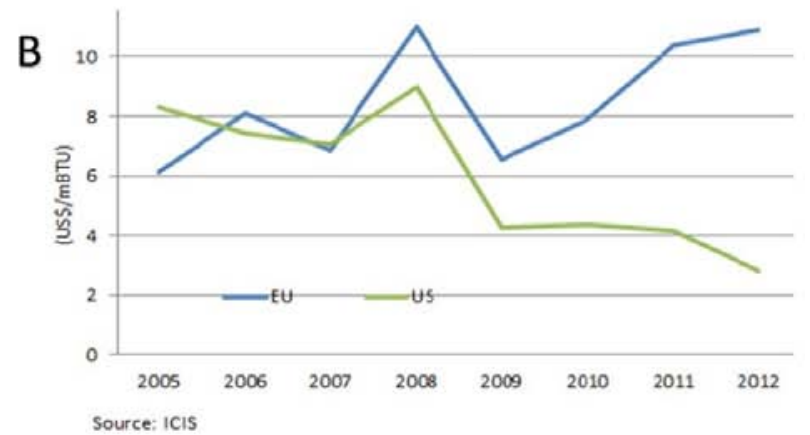

C

Henry Hub Natural Gas Spot Price

Doliars per Mitlion Btu

10.0

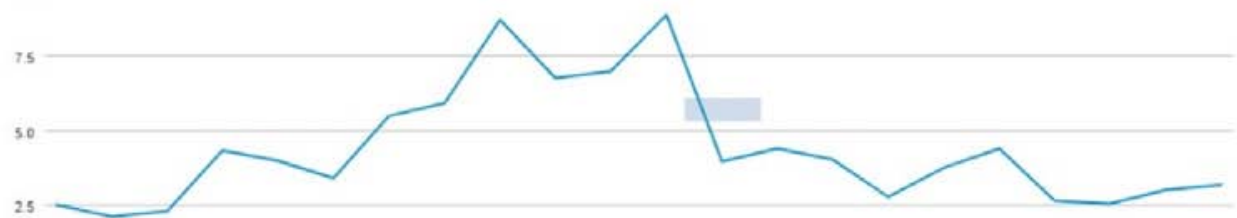

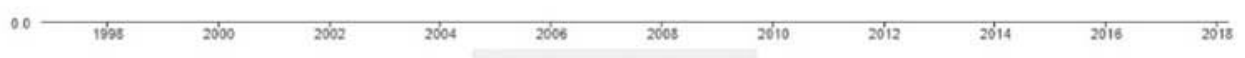

Figura 11. A: Precios de gas natural en USA frente al Europa Occidental (US/MMBTU). B: Evolución del precio de gas natural en EE.UU frente a la UE. C: Precios de gas natural a nivel mundial hasta el año 2018. Fuente: Regueiro, M., 2016; y U.S Energy Information Administration (en línea).

Figure 11. A: Natural gas prices in the USA vs Western Europe (US/MMBTU). B: Evolution of the price of natural gas in the US vs the EU (right). C: Worldwide natural gas price until 2018. Source: Regueiro, M., 2016; and U.S Energy Information Administration (on line).

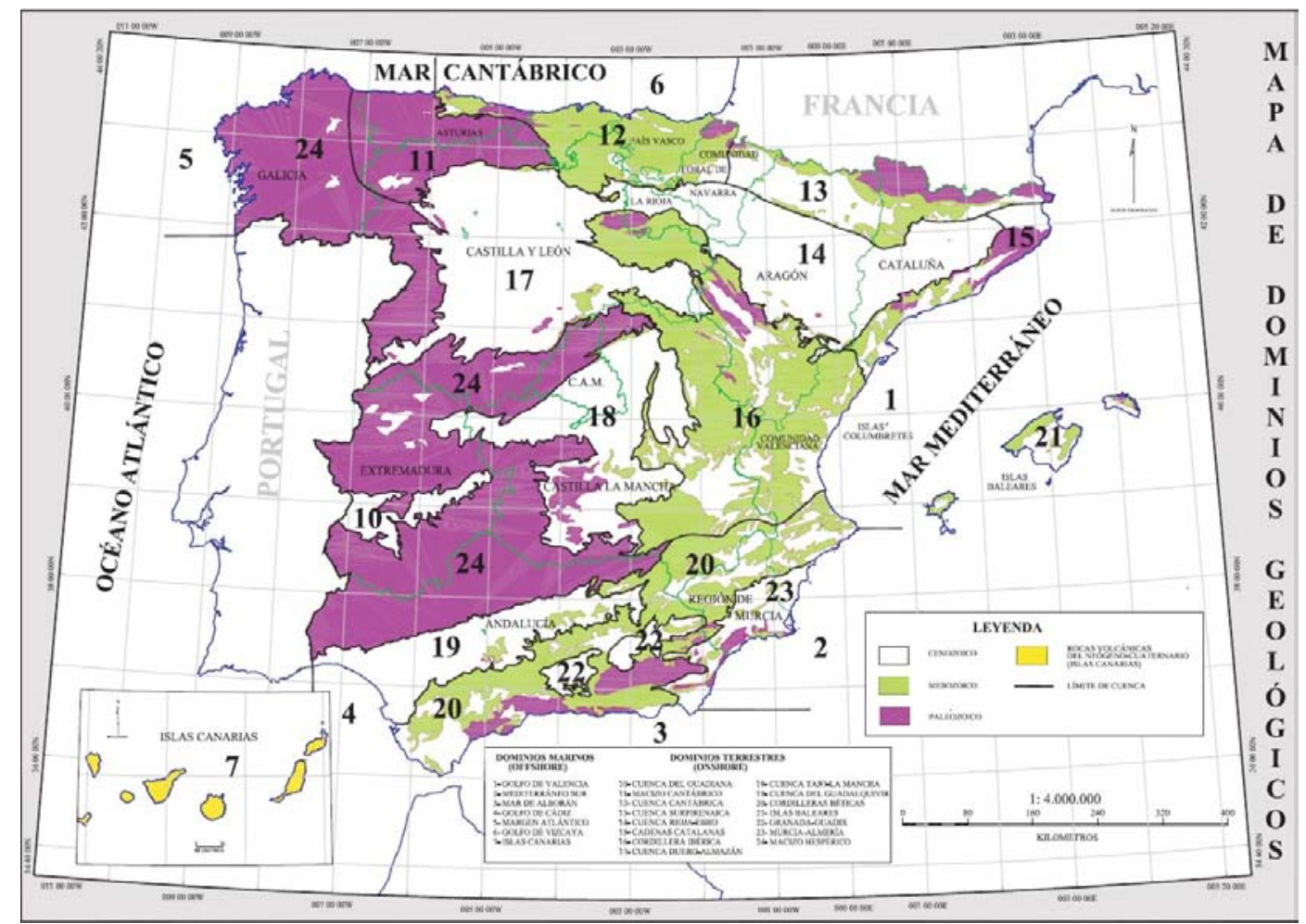

Figura 12. Mapa de distribucion de los dominios geologicos de España. Fuente: GESSAL, 2013.

Figure 12. Map of distribution of the geological domains of Spain. Source: GESSAL, 2013. 

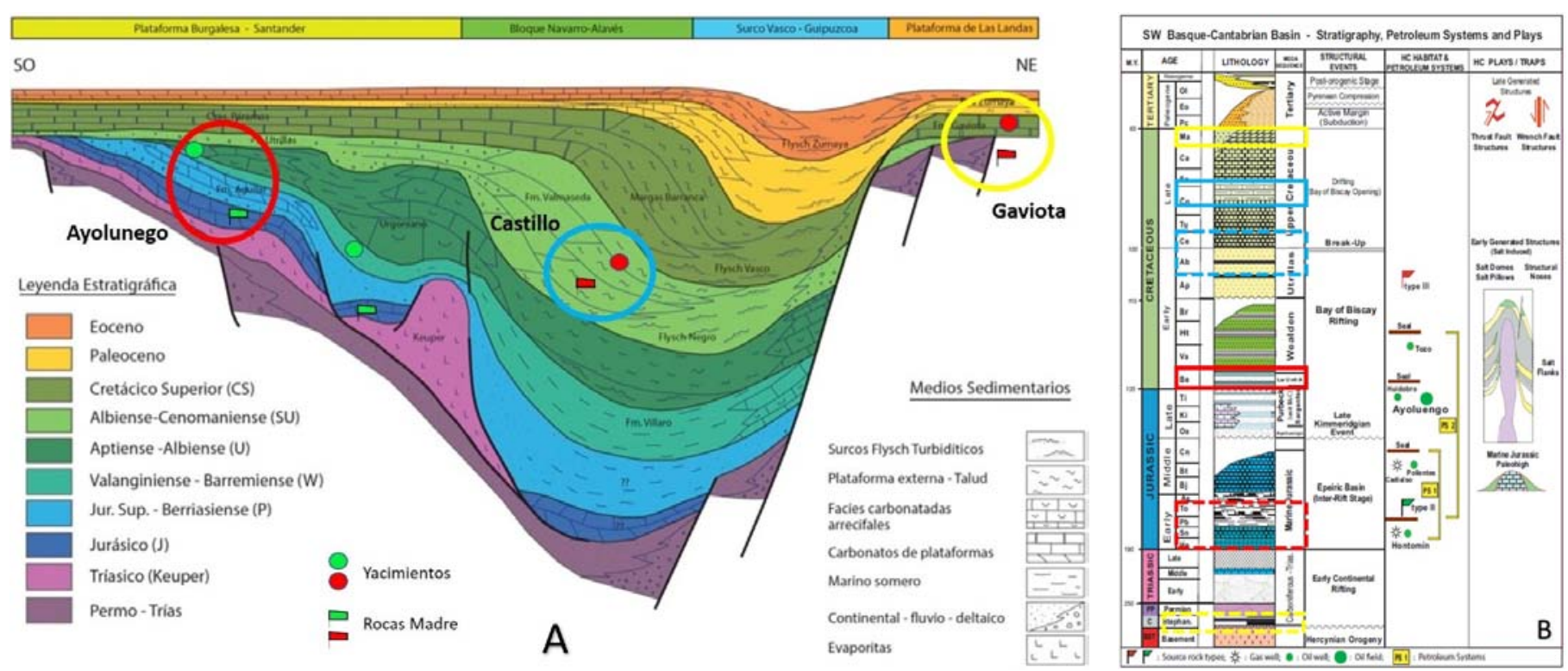

Figura 13. A: Esquema sedimentario general de la Cuenca Vasco Cantábrica. B: Esquema estratigráfico, sistemas petrolíferos y plays del surco de Sedano, al suroeste de la Cuenca Vasco-Cantábrica. Rocas madre (rectángulos discontinuos) y almacenes (rectángulos continuos) de los descubrimientos del gas del Castillo (azul), Ayoluengo (rojo), y Gaviota (amarillo). Modificado de Cámara, P., 2015; y de Beroiz, C., \& Permanyer, A. (2011); respectivamente.

Figure 13. A: General sedimentary scheme of the Basque-Cantabrian Basin. B: Stratigraphic scheme, petroleum systems and plays of Sedano furrow, southwest of the Basin Basque-Cantabrian. Mother rocks (discontinuous rectangles) and deposits (continuous rectangles) of the Castle gas discoveries (blue), Ayoluengo (red), and Gaviota (yellow). Modified Chamber, P., 2015; and de Beroiz, C., \& Permanyer, A. (2011); respectively.

del $1 \%$ en TOC entre la formación Balmaseda y la Enara Shale (US DPT OF ENERGY, 2015), indicando buenos potenciales de generación de hidrocarburo.

En la Cuenca Vasco-Cantábrica han tenido lugar diversos descubrimientos, como el del gas de Castillo en 1960, cuya roca madre corresponde a lutitas negras de edad Albiense-Cenomaniense, y el almacén, por encima de éstas, formado por calizas y areniscas fracturadas de edad Albiense SuperiorTuroniense. El campo de petróleo y gas de Ayoluengo descubierto en 1964, de roca madre jurásica (Lías) y almacén en el Purbeck (Titónico - Berriasiense), conocido ampliamente por ser el mayor campo petrolífero español. Así como el descubrimiento del campo de Gaviota en 1981, yacimiento formado en calizas y calcarenitas del Cenomaniense superior-Santoniense a partir de una roca madre carbonífera (Estefaniense), en facies de plataforma saturadas en gas y condensado. Por encima de ésta se encuentra la formación Zumaia, que actúa como sello, y por debajo aparecen arcillas negras y niveles de carbón de edades carboníferas (Estefaniense) que actuaron de roca madre. Estos últimos niveles contienen kerógenos de tipo IIIII en ventana de generación de gas húmedo en las zonas distales, ya que en la vertical se encuentran en ventana de petróleo (Cámara, P., 2015).
Además, se conocen varios casos aislados como el de Hontomín y Tozo, con producciones muy limitadas. Actualmente existen varios proyectos con múltiples permisos de exploración en marcha a lo largo de toda la región, tal y como se observa en la Figura 14.

\section{Macizo Hespérico}

Por otro lado, la Zona Cantábrica del Macizo Hespérico, con una superficie de $20.000 \mathrm{~km}^{2}$, se caracteriza por una sucesión paleozoica formada por una alternancia de formaciones carbonatadas y detríticas a grandes rasgos, con un gran potencial de generación de hidrocarburos. No obstante, dicho potencial no ha podido ser demostrado por los escasos dos sondeos perforados en la zona, que tuvieron resultados negativos.

Como puede observarse en la Figura 15, ya existen permisos de investigación de hidrocarburos no convencionales a lo largo de toda la Zona Cantábrica. Debido a la progresiva reducción del empleo del carbón hasta el cierre de todas las mineras de dicho material en España, en el principado de Asturias se han Ilevado a cabo evaluaciones del potencial de los yacimientos de gas del macizo cantábrico, contem- 


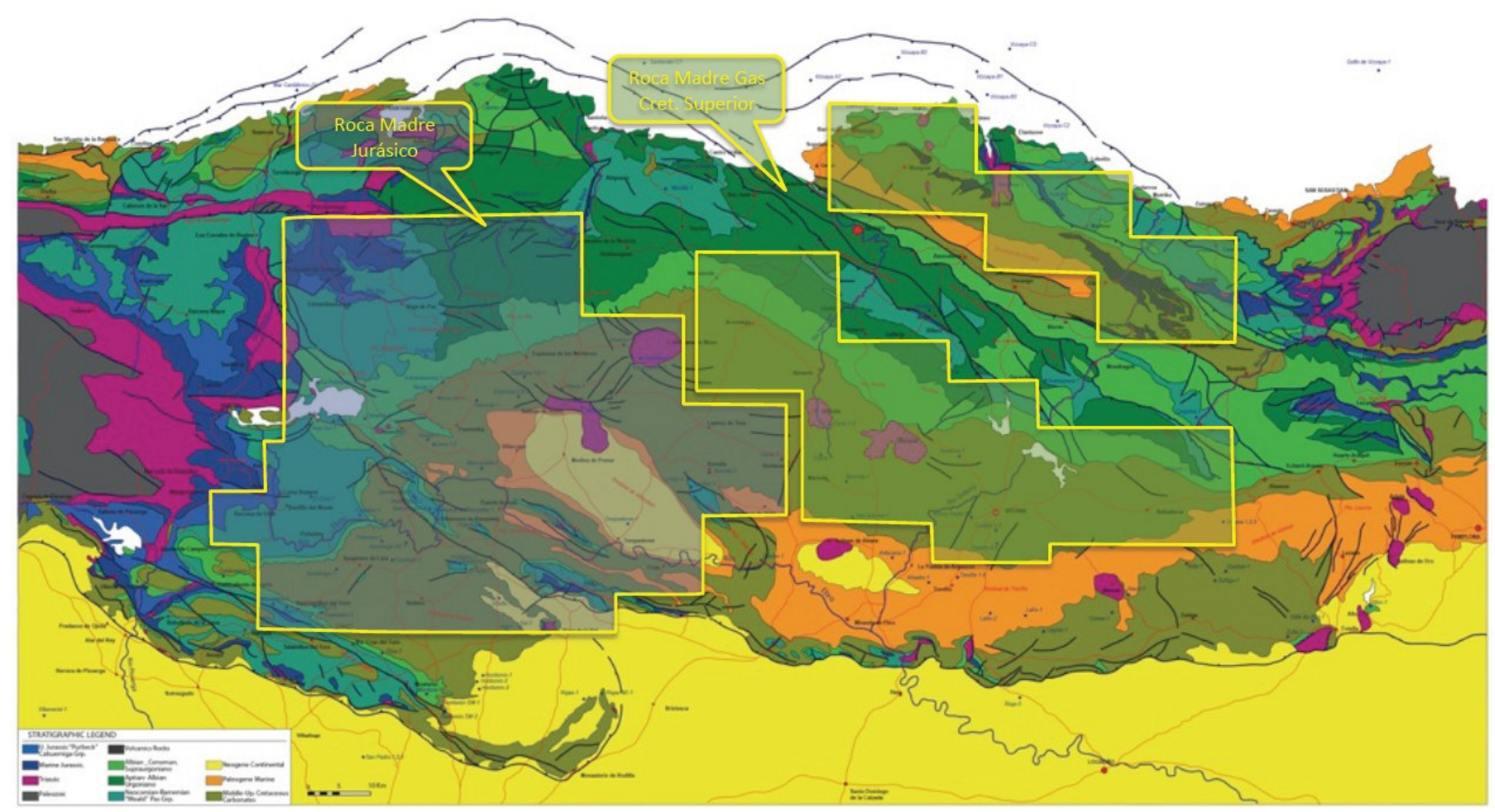

Figura 14. Mapa de las áreas prospectivas con "rocas madre" en la Cuenca Vasco-Cantábrica, situado sobre el mapa de permisos de exploración de la cuenca. Cámara, P. (2015).

Figure 14. Map of the prospective areas with "mother rocks" in the Basque-Cantabrian Basin, located on the map of exploration permits of the basin. Camera, P. (2015).

plando el aprovechamiento de gases como el metano de las capas de carbón (CBM), realizando sondeos profundos como el Asturias Central -1, o desgasificando capas de carbón de minas activas, como es el caso en el proyecto CARBOLAB, liderado por HUNOSA.

El gas natural asturiano se conoce desde las explotaciones de hulla del siglo $\mathrm{XX}$, a través de múltiples emanaciones mineras de dicho gas y las consecuencias que se sufrieron de las mismas, como roturas de varillaje por las enormes presiones a la que se encontraba, o igniciones de varios metros de altura que tardaron días en sofocarse.

La primera perforación en busca de yacimientos de gas se dio en 1967 por la empresa Ciepsa, con el sondeo Caldones-1, donde se reveló la presencia de gas, pero en cantidades no rentables. Mediante los sondeos posteriores de Asturias Central-1 y Modesta1, en los años 1992 y 1993 respectivamente, se demostró la presencia de gas, pero no se llegó a avanzar más en el proyecto.

El único estudio realizado hasta la fecha orientado a determinar la existencia y viabilidad de gas lutita en el Principado de Asturias fue realizado en el año 2014 por el Instituto Geológico y Minero de España (IGME). Para ello se basaron en Sistemas de Información Geográfica (SIG) y llevaron a cabo una considerable recogida de muestras, que posteriormente pasaron a análisis basados en criterios estratigráficos, litológicos y paleontológicos, estableciendo así varias formaciones de interés que pudieran contener gas lutita. Además, se basaron también en parámetros más detallados como el TOC o Ro para llevar a cabo una segunda selección más minuciosa. De esta forma quedaron definidas múltiples formaciones de interés, como: Fm. Pizarras de Luarca, Fm. Sueve, Fm. Formigoso, Fm Vegamián, Fm Alba, Fm Valdeteja, Fm Fresnedo, Grupo Sama, Grupo Lena, Fm Barcaliente y Fm San Emiliano (Martínez Orío, R., et al., 2014). Se deben destacar estas tres últimas, considerados como los niveles de mayor potencial.

\section{Otras zonas de interés}

También se estiman importantes reservas de gas lutita en Pirineos (260 BCM), que cuenta con 63 sondeos perforados y los ya descubiertos yacimientos de gas 

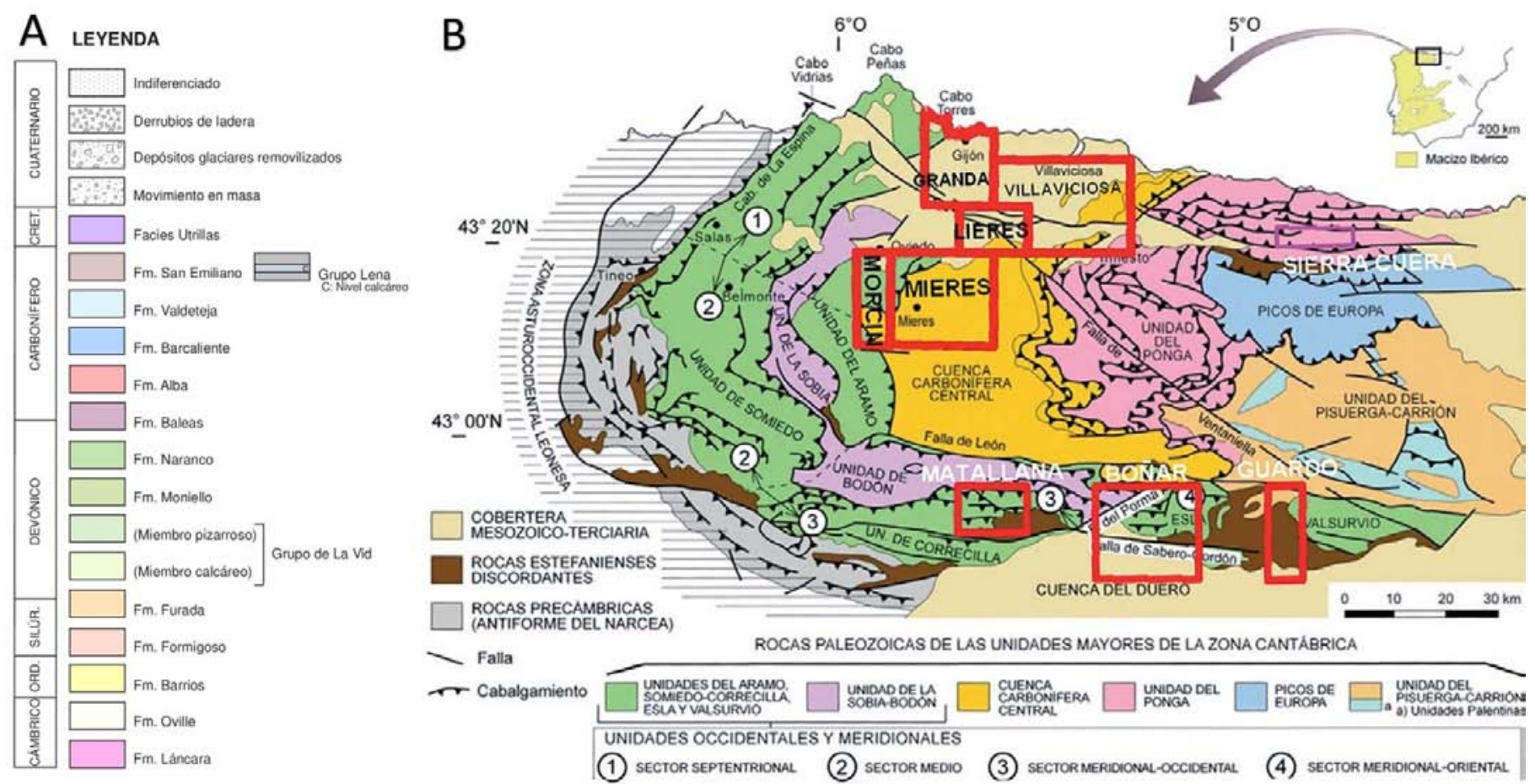

Figura 15. A: Columna estratigráfica representativa de las zonas de interés del macizo Hespérico. Fuente: Martínez Abad, I. (2007). B: Esquema estructural del Antepaís Paleozoico Cantábrico, con la posición de permisos de investigaciones de hidrocarburos vigentes marcados en rojo. Fuente: Modificada de Bastida (2004) y Aramburu et al. (1995), en Curbelo, J.L, et al, 2012.

Figure 15. A: A stratigraphic column representative of the areas of interest of the Hesperic massif. Source: Martínez Abad, I. (2007). B: Structural outline of the Cantabrian Paleozoic Foreland, with the position of current hydrocarbon research permits marked in red. Source: Modified by Bastida (2004) and Aramburu et al. (1995), in Curbelo, J.L, et al, 2012.

de Jaca y Serrablo; en la Cordillera Ibérica, con 95 $\mathrm{BCM}$ estimados, en donde se han perforado 18 sondeos sin hallazgos hasta la fecha; en la Cuenca del Guadalquivir, con estimaciones de 79 BCM, cuenta con 90 sondeos perforados y campos de gas descubiertos como el de Marismas, El Romeral y Las Barreras; la Cuenca del Duero, con estimaciones en $72 \mathrm{BCM}$ y 16 sondeos perforados, sin descubrimientos; y la Cuenca del Ebro, con estimaciones en torno a los 32 BCM y 41 sondeos perforados, con el descubrimiento del Yacimiento de Viura (ACIEP, 2013).

\section{Proyectos en España}

A pesar de no haberse realizado ningún sondeo exploratorio, y por tanto, ningún otro de explotación, en la actualidad existen múltiples permisos de investigación ya concedidos en varias Comunidades Autónomas (Figura 16), principalmente en País Vasco, Cantabria, Castilla y León (mayoritariamente en la provincia de Burgos), Comunidad Valenciana, La Rioja y Navarra (Prieto, J; 2014).

Existen varios proyectos en fase inicial que a día de hoy se encuentran completamente paralizados, como los proyectos "Urraca" y "Sedano", llevados a cabo por la empresa canadiense BNK Petroleum. También existe interés en el sistema kárstico de las Cuevas de Ojo Guareña en la provincia de Burgos, donde sigue pendiente un estudio detallado sobre las afecciones que podría sufrir la formación por la rotura de cimentaciones, para evitar su posible colapso por el peso de las instalaciones. Otro gran proyecto es el denominado Gran Enara, que incluye los permisos Enara, Angosto-1, Usoa, Mirua y Usapal. Este proyecto lo lleva a cabo SHESA y el Ente Vasco de la Energía (EVE), que llegaron a presentar documentos ambientales a fin de realizar sondeos exploratorios para la evaluación previa de la viabilidad productiva de las formaciones mencionadas, objetivo de este proyecto.

A pesar del cumplimiento de las compañías del sector con los protocolos estipulados por los organismos nacionales sobre la protección del medioambiente, subsisten graves dificultades para el desarrollo de las actividades correspondientes a las obligaciones con los Reales Decretos de Otorgamiento de los Permisos de Investigación. Es 


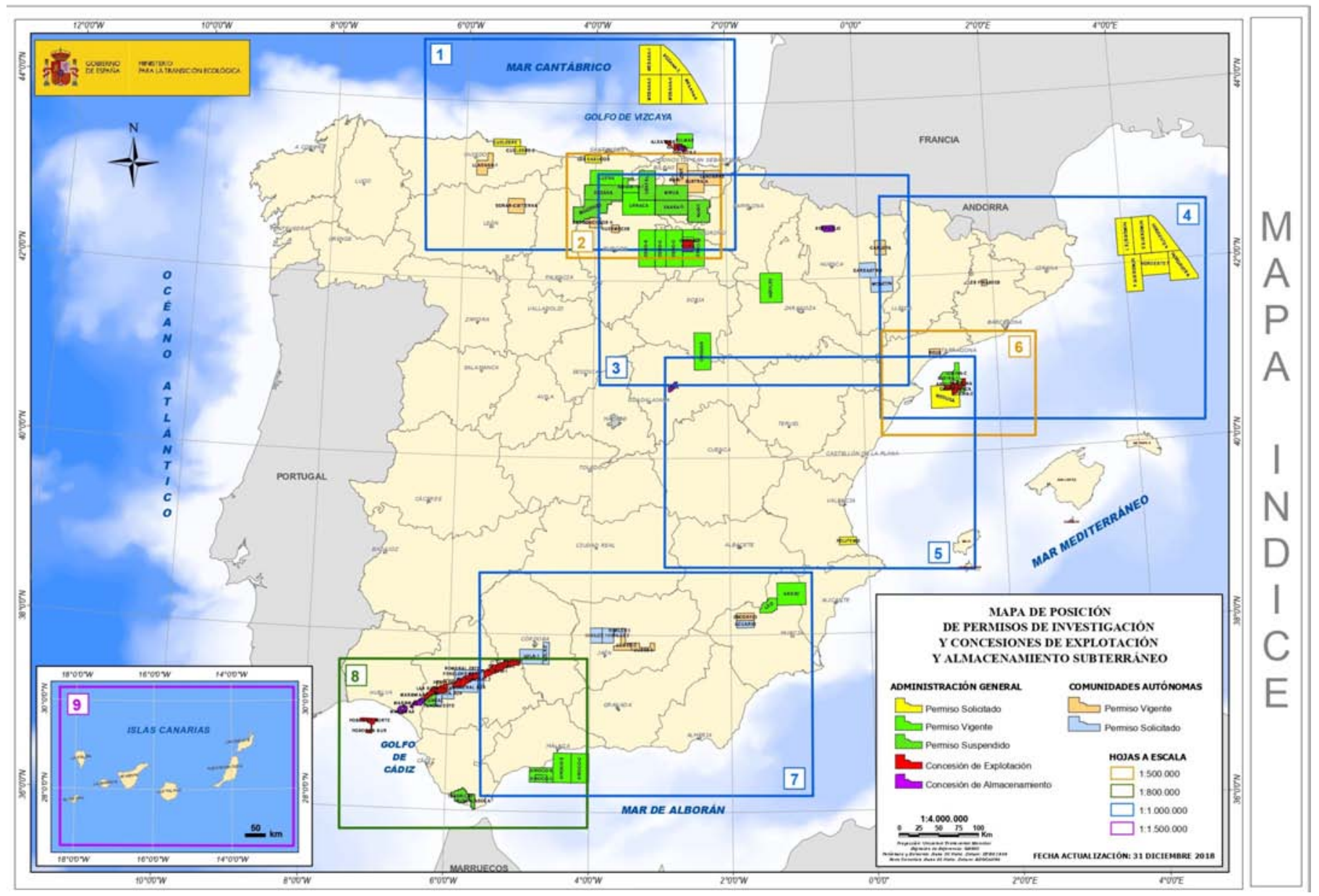

Figura 16. Mapa de los Permisos de E\&P de España 2018. Fuente: Secretaría de Estado de Energía (en línea). Figure 16. Map of E \& P Permits of Spain 2018. Source: State Secretary of Energy (on line).

por esto que las empresas inversoras para proyectos de exploración y explotación no cumplen con los tiempos estipulados (GESSAL, 2013). Dichas dificultades condicionan drásticamente el desarrollo de los trabajos básicos de exploración. Para obtener la "Declaración de Impacto Ambiental" se requieren largos trámites, y las compañías operadoras encuentran múltiples dificultades en las distintas administraciones que gestionan la tramitación de los permisos de investigación. Esto es debido a la diversidad de actuación o a solapes de funciones entre distintas administraciones locales, autonómicas y nacionales y la interpretación de la regulación actual.

Como consecuencia de esto último, así como de los bajos precios del gas actual y el fuerte rechazo social que se ha desarrollado en el país, muchas de las empresas encargadas de estos proyectos han renunciado en su intento de conseguir aplicar en España la técnica de fracturación hidráulica y abandonado el país, a la espera de que las condiciones políticas y de receptividad social sean propicias para continuar con los proyectos.

Los proyectos Urraca y Sedano pueden servir de ejemplo. En 2014, BNK Petroleum presentó los permisos para realizar los primeros pozos exploratorios y así confirmar la presencia de gas natural. Previo a dichos sondeos se debía superar la tramitación ambiental que arranca con la apertura del proceso de información pública para que instituciones, ONGs y particulares puedan alegar. De esta forma se estableció en la Ley de Impacto Ambiental aprobada por el Gobierno Central a finales de 2013. En 2014 el PP modificó durante su mandato varias normas para incentivar la técnica de la fracturación hidráulica. No obstante, tras las elecciones de diciembre 2015, la nueva mayoría en el congreso instó al gobierno a anular dichas normas y pedir además la derogación de "todos aquellos artículos que favorecen" el fracking, así como a prohibir su uso y a suspender los permisos expedidos (Planelles, M; en línea). Como 
consecuencia, BNK junto a varias compañías renunciaron a varios de sus permisos, y ya en 2018, en el Boletín Oficial de Castilla y León se publicaron las resoluciones de la Consejería de Economía y Hacienda en las que acepta los desistimientos de las compañías (Escribano, S; 2018, en línea).

\section{Legislación}

Obtener hidrocarburos en España requiere la titularidad de concesiones del Estado, que se rigen por una serie de leyes aprobadas a lo largo de todo el desarrollo energético del país. Así pues, las reglas para extraer recursos de gas lutita en España siguen unas pautas que comenzaron con la Ley sobre investigación y explotación de hidrocarburos de 1958, posteriormente modificada por el Real Decreto 2362/1976 de 30 de julio. Más tarde, esta Ley quedó derogada por la nueva Ley 34/1998, de 7 de octubre, actual ley vigor. Esta nueva ley ha sufrido cambios parciales a lo largo de los años siguientes, apareciendo la Ley 12/2007 de 2 de junio, la Ley 17/2013 de 29 de octubre, y la última modificación, la Ley 8/2015 de 21 de mayo.

El uso de técnicas de fracturación hidráulica se introdujo por primera vez con la Ley $17 / 2013$, con objeto de garantizar un suministro e incremento de la competencia española en el sector energético. Hasta entonces, desde el punto de vista jurídico no se distinguía diferencia alguna entre fuentes de gas convencional y no convencional, y por ello se aplicaba el mismo régimen legal que el de exploración, investigación y explotación de hidrocarburos, independientemente de las técnicas que se realizasen para ello. Con la última ley, la Ley $8 / 2015$, se regulan medidas tributarias y no tributarias con respecto a la exploración, investigación y exploración de hidrocarburos. Se establecen impuestos sobre el Valor de Extracción de Gas, Petróleo y Condensados, se distingue entre extracción convencional y no convencional, y respecto al otorgamiento de las concesiones de explotación, se asignan beneficios a los ayuntamientos y propietarios de los terrenos donde se hagan sondeos con la técnica de fracturación hidráulica.

Por otro lado, la regulación ambiental apareció en 1986 al integrarse España en la UE, y fue actualizada en profundidad por el Real Decreto Legislativo $1 / 2008$, de 11 de enero, por el cual se aprobaba la Ley de Evaluación de Impacto Ambiental de proyectos; y la Ley 6/2010, de 24 de marzo, que modificaba el Real Decreto Legislativo 1/2008. Actualmente se encuentra en vigor la Ley de Evaluación Ambiental 21/2013, de 9 de diciembre. Las EIA (Evaluación de Impacto Ambiental), realizadas por las conserjerías de medio ambiente de las Comunidades Autónomas (CCAAs), se encargan de proyectos individuales presentados por empresas públicas o privadas, y aquellos presentados por las administraciones se llevan a cabo por la evaluación ambiental estratégica, regulada por la Ley 9/2006, de 28 de abril, que establece los plazos máximos a cumplir.

Cuando finaliza todo el proceso de regulación ambiental, es el Ministerio de Agricultura y Pesca, Alimentación y Medio Ambiente (MAPAMA) el que aprueba o autoriza finalmente la evaluación ambiental de planes, programas o proyectos que son competencia del Estado; o aquellos organismos elegidos por las CCAA cuando sean éstas las que deban llevar a cabo la evaluación. Muchas empresas intentan acogerse a la legislación ambiental solicitando permisos de exploración o de investigación cuya área se extienda en al menos dos comunidades autónomas. Entonces interviene el ministerio de industria, más resolutivo que muchas dependencias autonómicas que no tienen experiencia ni antecedentes en la concesión de proyectos.

Por otro lado, están los permisos de investigación que se conceden a las empresas. Un permiso de investigación otorga al titular derechos de exploración exclusivos en el área del permiso, con una superficie mínima de 10.000 hectáreas y máxima de 100.000 , durante un periodo inicial de seis años, prorrogable por otros tres con la obligación, en este caso, de renunciar a un $50 \%$ de la superficie original del permiso. Asimismo, un permiso concede el derecho a obtener, posteriormente, una concesión de explotación, si se descubre una acumulación de hidrocarburos comercialmente explotable.

El otorgamiento de una concesión de explotación confiere a sus titulares el derecho exclusivo de explotar los hidrocarburos descubiertos en la zona, llevando a cabo para ello las actividades que sean necesarias (que previamente han de ser aprobadas por el Ministerio de Industria, Comercio y Turismo) para explotar adecuadamente el recurso durante un periodo inicial de treinta años, ampliable por dos periodos adicionales de diez años cada uno.

Por ello, el marco legal que abarca este tema, a nivel nacional, viene dictaminado principalmente por las siguientes leyes:

- El Real Decreto 2362/1976 de 30 de julio, por el que se aprueba el Reglamento de la Ley sobre investigación y explotación de hidrocarburos de 27 de junio de 1974.

Debido a los avances producidos tanto en el ámbito económico como tecnológico, este decreto pretende actualizar la ley de 1958. Agiliza los procesos administrativos como la 
transmisión de permisos, se actualizan conceptos como la referencia a coordenadas geográficas del meridiano de Greenwich y realiza las inversiones propicias conforme el cambio de pesetas a euros.

Aprueba la Ley sobre Investigación y Explotación de Hidrocarburos de 27 de Junio de 1974, que describe detalladamente los requisitos necesarios para los proyectos de exploración, investigación, explotación, refino, transporte, almacenamiento y comercialización de hidrocarburos tanto líquidos como gaseosos, entre otras funciones.

- Ley 34/1998, de 7 de octubre, del sector de hidrocarburos (BOE 8/10/1998):

Mediante esta ley, se pretende planificar la normativa legal vigente en materia de hidrocarburos, ya sea en exploración, investigación, explotación, comercio, transporte y suministro de los mismos. Además, pone en consideración de bienes de dominio público estatal aquellos yacimientos y almacenes dentro del territorio del Estado, acorde con el artículo 132.2 de la Constitución Española de 1978; y establece las competencias de las autoridades reguladoras, así como la coordinación con planes urbanísticos y de infraestructuras viarias.

La ocupación deberá contar con el acuerdo de la Delegación Provincial del MINETUR, y todos aquellos que quieran solicitar permisos y concesiones de exploración, deberán proporcionar la información requerida por MINETUR y la Administración autonómica competente.

Por otro lado, esta ley introduce criterios de protección del medio ambiente y concede a las Comunidades Autónomas las autorizaciones y permisos de investigación circunscritos a su propio territorio.

- Real Decreto Legislativo 1/2008, de 11 de enero, por el que se aprueba el texto refundido de la Ley de Evaluación de Impacto Ambiental de proyectos. A excepción de las perforaciones cuyo fin sea investigar el estado y estabilidad de suelos, los proyectos públicos y privados deberán someter a una evaluación de impacto ambiental a todas aquellas obras, instalaciones o a cualquier otra actividad relacionada. Posteriormente se modifica, dando lugar a la Ley de Evaluación Ambiental 21/2013.

A todo esto, hay que añadir que en febrero de 2019 se aprobó el anteproyecto de Ley de Cambio Climático y Transición energética que contempla la descarbonización al 100 por 100 de la economía española en 2050. Así pues, el futuro de la exploración de gas de lutita en España está por ver, ya que, si la ley entra en vigor, no se darán autorizaciones para explorar, investigar hidrocarburos o nuevas concesiones ni en tierra ni en aguas territoriales, ni tampoco se podrán desarrollar proyectos de fracturación hidráulica (Valencia Plaza, en línea).

Con respecto al marco regulatorio europeo, la UE ha entrado de lleno en el debate sobre la fracturación hidráulica, y ha llevado a cabo numerosos estudios desde distintas perspectivas, siendo las medioambientales y jurídicas las fundamentales. Se han elaborado numerosos documentos acerca del tema y en general el fracking ha sido evaluado favorablemente, sin olvidarse de todos aquellos riesgos que presenta esta técnica. De entre todos esos documentos, los de mayor relevancia sobre el tema son:

- El Informe sobre impactos ambientales de actividades de extracción de petróleo y gas lutita, del Comité de Medio Ambiente, Salud Pública y Seguridad, aprobado por el Parlamento Europeo en el año 2012. En él, se aboga por una correcta planificación de los proyectos, así como un constante seguimiento y elaboración de informes. Se reconocen que los tipos de roca presentes determinan el diseño y métodos de los trabajos de extracción, y señala que la fracturación hidráulica, si bien es cierto que hace uso de volúmenes de agua muy importantes, no lo son en exceso si se comparan con otros sectores industriales. Sostiene que la principal cuestión relativa a la contaminación de las aguas subterráneas, uno de los factores de mayor riesgo, dependen de la integridad de los pozos, la calidad del revestimiento y de la cementación. Y por ello, hace hincapié en que se deban cumplir todas las normas sobre la construcción de pozos en el más estricto de los sentidos.

En este informe se reconoce también que la técnica ha protagonizado numerosos accidentes en EEUU (aunque porcentualmente muy minoritarios ante el enorme número total de actuaciones) que han puesto en riesgo el medio ambiente y la salud humana durante su aplicación. No obstante, la mayoría de estos problemas se han debido a manipulaciones incorrectas que pueden evitarse. Y es que la regulación normativa con respecto al seguimiento y supervisión de las operaciones es bastante deficiente; por ello es necesaria una supervisión adecuada.

En sus conclusiones, insta que sea necesaria una diversificación en el suministro energético y reducir la dependencia energética externa, 
estimulando el crecimiento económico. Por ello, si la UE quiere apostar fuertemente a favor del fracking, antes son necesarias serias reformas legislativas para mejorar las normas vigentes.

- Las Recomendaciones de la Comisión sobre principios mínimos para la exploración y explotación de hidrocarburos (como el gas lutita) con fracturación hidráulica de alto volumen de la Comisión Europea en 2014. Hasta entonces no había ni una sola norma europea que tratase de forma específica el tema de la fracturación hidráulica, y es en este informe donde se señala el potencial de los hidrocarburos no convencionales en la UE, así como los principales elementos que garanticen la seguridad de dicha técnica.

No obstante, esto es tan solo una recomendación y por lo tanto no vinculante. Respeta el derecho de cada Estado miembro, de determinar las condiciones de explotación de sus recursos energéticos, sus posibilidades de elegir entre distintas fuentes de energía y la estructura general de su abastecimiento energético (art. 194.2 TFUE).

(Fuentes: Serrano González, M., 2015; Cayola Cortés, F. J., 2014; Gil Villamer, P. L; 2014; y Boletín Oficial del Estado -en línea-).

\section{Preocupaciones en torno a la fracturación hidráulica}

Tal y como expone el trabajo realizado por ÁlvarezFernández et al. (2013), la importación de hidrocarburos en España ha sido un verdadero lastre para su propio crecimiento económico. Debido al escaso potencial energético que presentaba nuestro país, siempre se ha considerado como algo irreversible. No obstante, gracias al desarrollo de la tecnología y las técnicas de extracción, hoy en día sí se presenta con un potencial destacable, por lo menos con vistas a obtener una cierta independencia energética en cuanto a gas natural se refiere.

Como en toda actividad industrial, ya sea extractiva (mineral, petróleo, gas) o transformadora (química, alimentaria), existen riesgos ambientales, de seguridad o de salud. Es por esto que, como cualquier otra actividad humana, los riesgos deben gestionarse de forma eficiente a través de rigurosos estudios de investigación, la mejora de las técnicas y optimización de la maquinaria, así como la instauración de sistemas que lo regulen. Todo riesgo debe ser estudiado con minuciosidad, con el objetivo de prevenir, mitigar o incluso evitar el problema.
En España partiríamos de la experiencia estadounidense referente a la fracturación hidráulica y extracción de gas no convencional, país que dispone de más de 200.000 pozos productores de gas no convencional, y de todo el conocimiento adquirido durante las más de 2 millones de fracturaciones hidráulicas realizadas por todo el mundo (comunicación personal: Álvarez Fernández, I.).

De los 200.000 pozos productores estadounidenses, la Agencia de Protección Ambiental de Estados Unidos (EPA) ha denunciado 40 incidentes medioambientales en explotaciones de gas no convencional en 10 estados de USA (Figura 17). Como se puede observar, el mayor número de incidentes estaban relacionados con derrames en superficie y con la construcción de los pozos, siendo mucho menos frecuentes aquellos relacionados con la cantidad de agua empleada, el tratamiento y retirada del agua de retorno, migraciones no controladas desde la zona de fractura o pozos abandonados. (Según Puls, R., 2012, en Álvarez Fernández, I., 2017).

De esto se deduce que, si se consigue asegurar la estanqueidad del pozo y un correcto control de las balsas de superficie, se podrían evitar el $85-90 \%$ de los problemas de contaminación de acuíferos que tanto preocupan a la población.

\section{Vertidos en superficie y fugas en el subsuelo}

A fin de solventar dicho problema, el "Federal Ministry for the Enviroment, Nature Conservation and

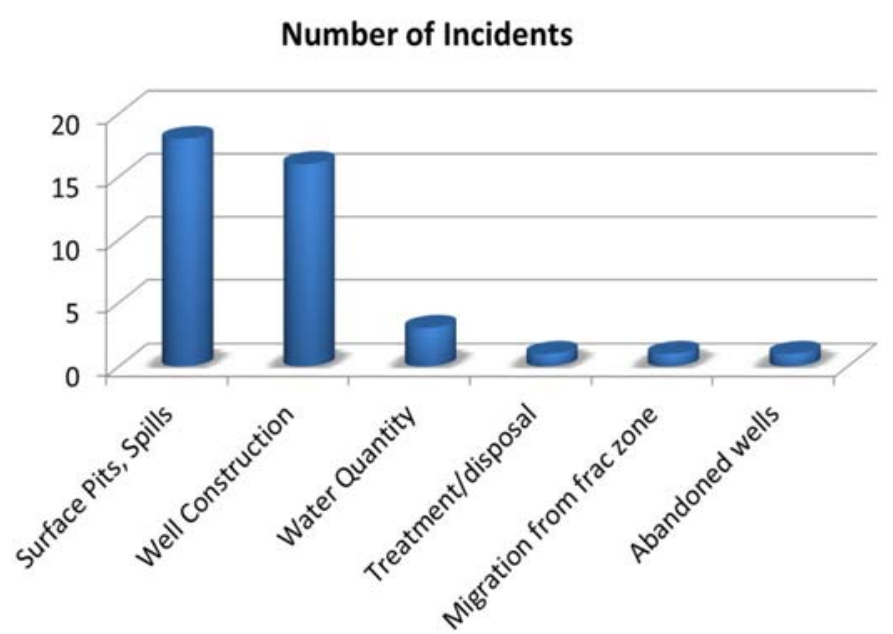

Figura 17. Números de incidentes y sus causas, denunciados por la EPA. Fuente: Puls, R. (2012), en Álvarez Fernández, I., 2017.

Figure 17. Numbers of incidents and their causes reported by the EPA. Source: Puls, R. (2012), in Álvarez Fernández, I., 2017. 
Nuclear Safety of Germany" Ilevó a cabo un estudio del control de dirección del agua que se introduce en el terreno con sus respectivos aditivos, identificando las posibles fugas que pudieran existir (Álvarez Fernández, I., 2017), como se ilustra en la Figura 18.

Para prevenir dichas fugas en superficie (Vía 0) se recomienda el empleo de tanques en lugar de balsas para almacenar el fluido de fracturación, así como la instalación de geotextiles (membranas impermeables) que recubran toda el área de trabajo. Por otro lado, para evitar fugas a través de la tubería del pozo (Vía 1) se debe asegurar una correcta estanqueidad del pozo, y para ello se recomienda la instalación de al menos una tubería superficial a modo de protección de acuíferos, así como de otra tubería intermedia donde quede atrapado el gas evitando que éste pueda entrar en contacto con los acuíferos. Además, todo el procedimiento debe ir acompañado de una constante monitorización sísmica en tiempo real durante la inyección del fluido y las operaciones de fracturación.

También es necesario llevar a cabo un estudio de las condiciones geomecánicas del subsuelo ya que, de no hacerlo, podrían darse vertidos a través de fallas conectadas por donde podría migrar el fluido (vía 2). Mostramos a modo de ejemplo, que llevar a cabo la fracturación hidráulica en regiones como la Cordillera Ibérica podría suponer un problema debido al gran número de fallas que la componen y a la relación entre los acuíferos y las capas que se consideran roca madre. No sucede así en la Cuenca VascoCantábrica, donde las capas donde se encuentra acumulado el gas se estiman a importantes profundidades, donde el riesgo de migración por fracturas es mínimo (comunicación personal: Pieren, A.).

Por último, también se tiene en cuenta la vía de tipo 3, que hace referencia a todo el resto de vertidos que puedan migrar al cabo de miles de años por difusión, y como cabe pensar, no existen precedentes de este tipo en EE.UU.

\section{Requerimientos de agua}

Otro factor muy importante a tener en cuenta, son los requerimientos de agua necesarios para llevar a cabo

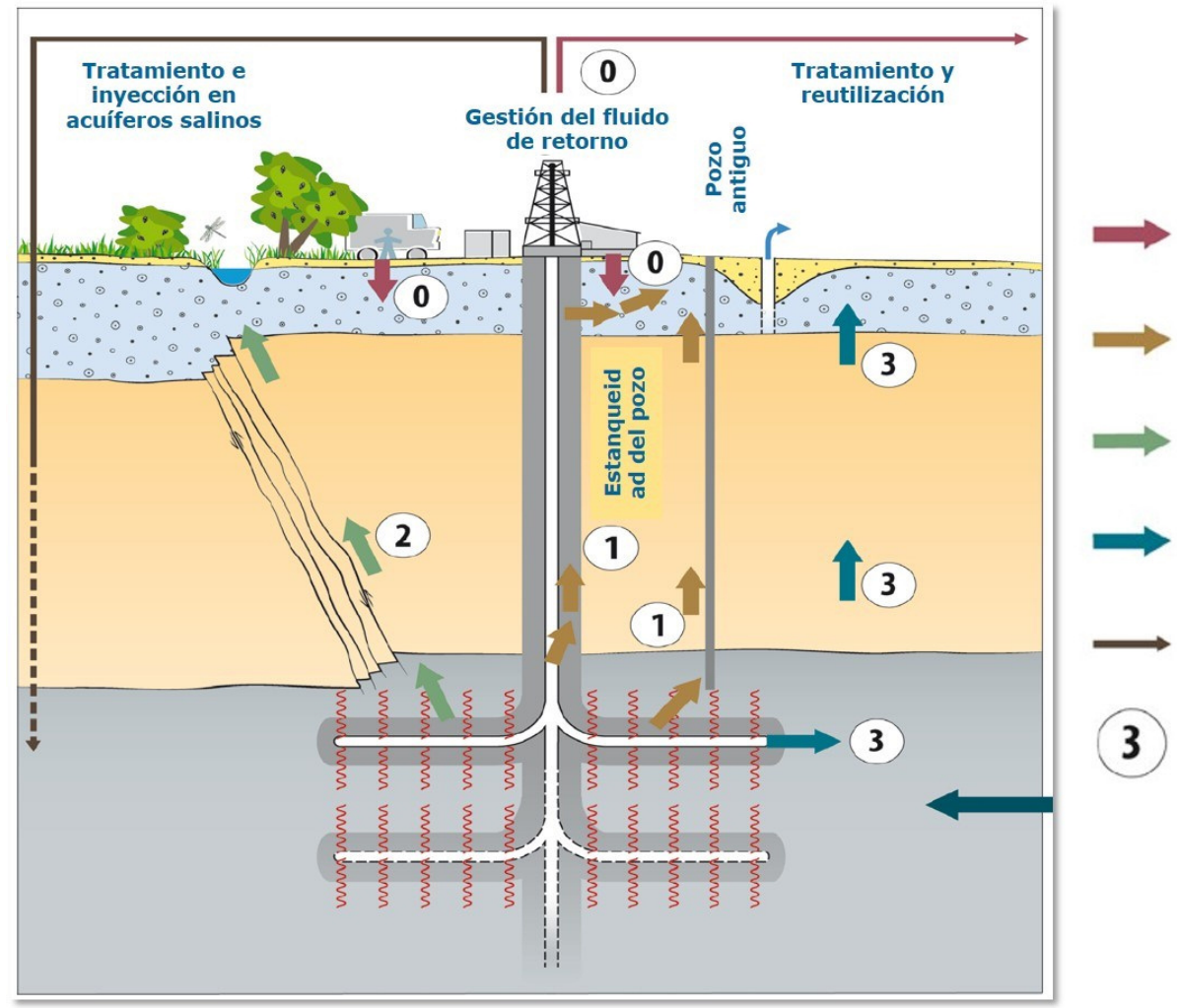

Vertido incontrolado en superficie. Camino tipo 0

Migración por vías no naturales. Camino tipo 1

Migración a través de fallas. Camino tipo 2

Migración/difusión sin necesidad de vías especiales. Camino tipo 3

Inyección del fluido de retorno en acuíferos profundos

Tipos de caminos de migración/difusión

Figura 18. Vías teóricas de migración/difusión del fluido de fracturación. Fuente: Federal Ministry for the Environment, Nature Conservation and Nuclear Safety of Germany, en Álvarez Fernández, I., 2017.

Figure 18. Theoretical pathways of migration / diffusion of fracturing fluid. Source: Federal Ministry for the Environment, Nature Conservation and Nuclear Safety of Germany, in Álvarez Fernández, I., 2017. 
el proceso de fracturación hidráulica. En una sección horizontal de cada pozo se suelen realizar entre $10 \mathrm{y}$ 20 fracturas, y se requieren entre 500 y $1.000 \mathrm{~m}^{3}$ de agua por fractura (prácticamente, el mismo consumo que se emplea en técnicas convencionales). Posteriormente, entre el $30 \%$ y el $60 \%$ del fluido inyectado retorna a superficie en los primeros días. En términos relativos, suponiendo un consumo medio de $10.000 \mathrm{~m}^{3}$ de agua por pozo, el proceso de fracturación hidráulica equivale a 2 semanas de regadío en un campo de golf de 18 hoyos, 6 horas de funcionamiento en una central de carbón o 3 horas de una Central Nuclear de $1000 \mathrm{Mw}$, o a 9 minutos de consumo en la Comunidad de Madrid. Además, la demanda de agua se reduce mediante el reciclado del agua que retorna a superficie, utilizando un agua no potable y con la mejora de las tecnologías, cada vez menos exigentes en agua (fuente: Álvarez Fernández, I., 2017).

\section{Emisión de gases contaminantes}

La emisión de gases de efecto invernadero durante la extracción del gas también es digna de debate. $Y$ es que algunos estudios afirman que la sustitución de gas natural por el carbón no es un medio eficaz para reducir la magnitud del cambio climático. Un ejemplo de ello es el estudio realizado en 2011 porTom Wigley, investigador del Centro Nacional de Investigación Atmosférica (NCAR). Se basa en que, si bien es cierto que el empleo de gas natural reduce las emisiones de $\mathrm{CO}_{2}$ casi en un $50 \%$ respecto al carbón, también genera escapes de metano durante las operaciones de extracción, gas cuyo efecto invernadero supera entre 20 y 25 veces al del $\mathrm{CO}_{2}$. Por otro lado, también pueden encontrarse múltiples investigaciones afirmando que la explotación de hidrocarburos no convencionales no genera emisiones superiores a las que producen las explotaciones convencionales y que, si la perforación, entubación y cimentación del pozo se realizan correctamente, las emisiones fugitivas de metano pueden evitarse (García Portero, J., 2013).

De una forma u otra, las emisiones producidas por la técnica de fracturación hidráulica son muy limitadas en comparación con el verdadero problema: la emisión de hidratos de metano previamente congelados por la descongelación de los polos y del permafrost (capas de suelo permanentemente congelado), debido todo a ello al calentamiento global y las posibles emanaciones de metano liberado de los clatratos por calentamiento del agua en los fondos oceánicos.

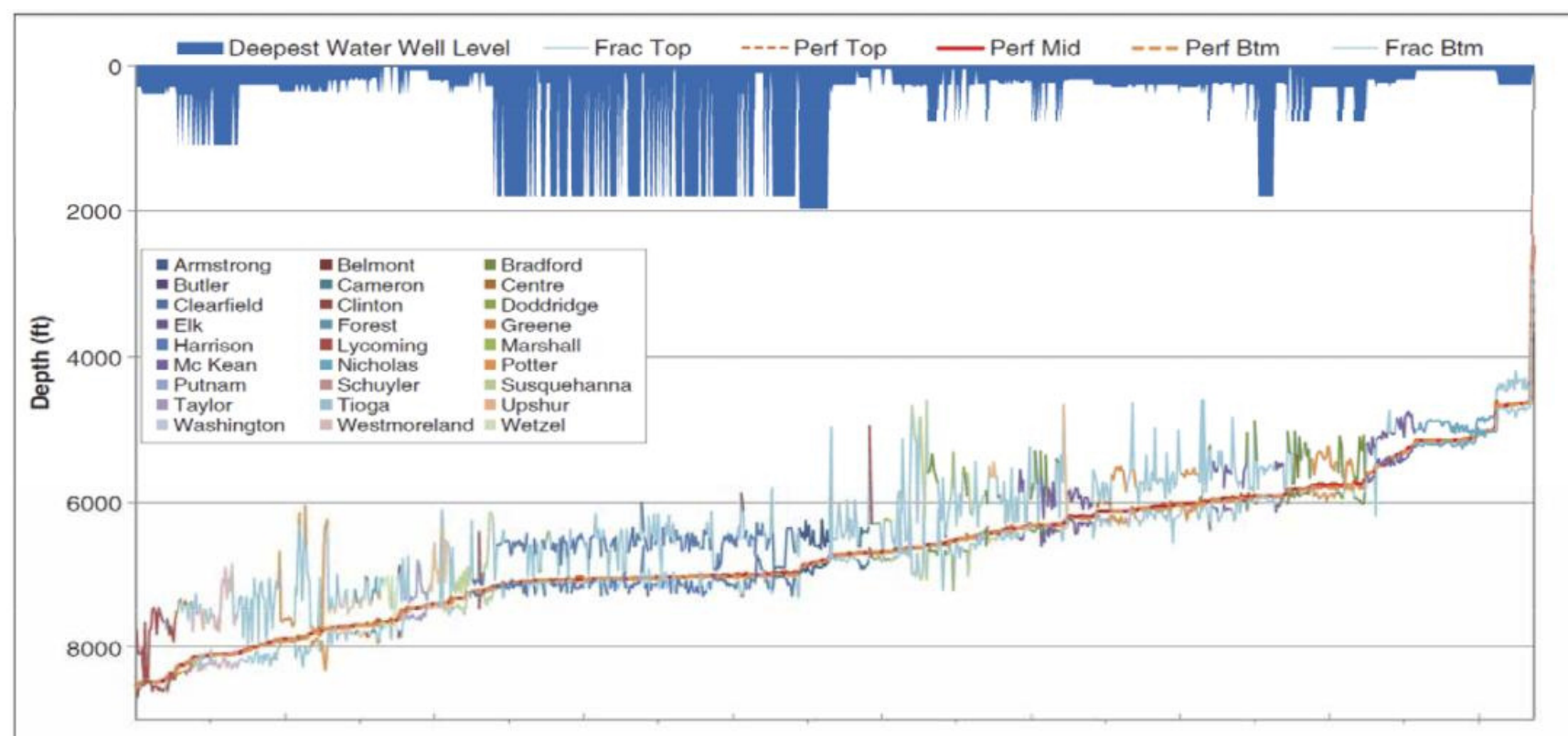

Frac Stages (Sorted on Perf Midpoints)

Figura 19. Estudio microsísmico de la cuenca Marcellus Shale (EE.UU). En rojo se representa la profundidad de la zona a fracturar, las líneas quebradas en azul representan la extensión de las fracturas, y arriba en azul oscuro se representa la profundidad de los acuíferos que abastecen a la población. Fuente: Alameda, D. 2014.

Figure 19. Micro-seismic study of the Marcellus Shale basin (USA). Red lines show the depth of the zone to be fractured, the blue lines represent the extension of the fractures, and at the top dark blue represents the depth of the aquifers that supply the population. Source: Alameda, D. 2014. 


\section{Riesgos-Mitos}

Dejando de lado los posibles problemas a los que debería enfrentarse la explotación de gas de lutita en España, aún queda un largo recorrido para reducir los actuales mitos que envuelven a este recurso energético. Como por ejemplo, aquellos referentes al elevado potencial de sismicidad; o a que las fracturas generadas alcancen acuíferos superficiales y que los fluidos de fracturación no extraídos se difundan hasta ellos. La sismicidad producida por la fracturación hidráulica es mínima, y solo existen probabilidades remotas de que generen sismos de hasta grado 2 en la escala de Ritcher, sin llegar a ser perceptibles en la localización donde se produzcan (son perceptibles a partir de grado 3 ). Con respecto a la propagación de fracturas y difusión de fluidos de fracturación sobrantes, los acuíferos de abastecimiento se encuentran a menos de $400 \mathrm{~m}$ de profundidad, y las fracturas se propagan un radio aproximado de $200 \mathrm{~m}$ alrededor del pozo, dejando, por lo general, 2000 o 3000 metros de roca suprayacente entre fracturas y pozo que impiden cualquier difusión de fluidos.
Un ejemplo de ello es el caso de la bien documentada Marcellus Shale (EE.UU). Mediante microsísmica se pudo conocer la longitud de las fracturas y descubrir si estas alcanzaron acuíferos o no. De esta forma se observó que durante el proceso de fracturación hidráulica se produjeron sismos del orden de -1 y -2 en la escala de Ritcher, intensidad insuficiente para alcanzar acuíferos superficiales (siempre y cuando se realice adecuadamente y a una distancia prudente). Tal y como muestra la Figura 19, en la cuenca Marcellus existen más de 2000 pies de separación $(\approx$ $600 \mathrm{~m}$ ) entre los acuíferos subterráneos y las fisuras generadas.

\section{Oposición en España}

Debido a toda la polémica que rodea a la técnica de fracturación hidráulica, la oposición de grupos conservacionistas y a la fuerte concienciación sobre el cambio climático que inunda internet, se ha desarrollado una fuerte desconfianza sobre dicha técnica en el país. $Y$ es que existen una infinidad de enfoques

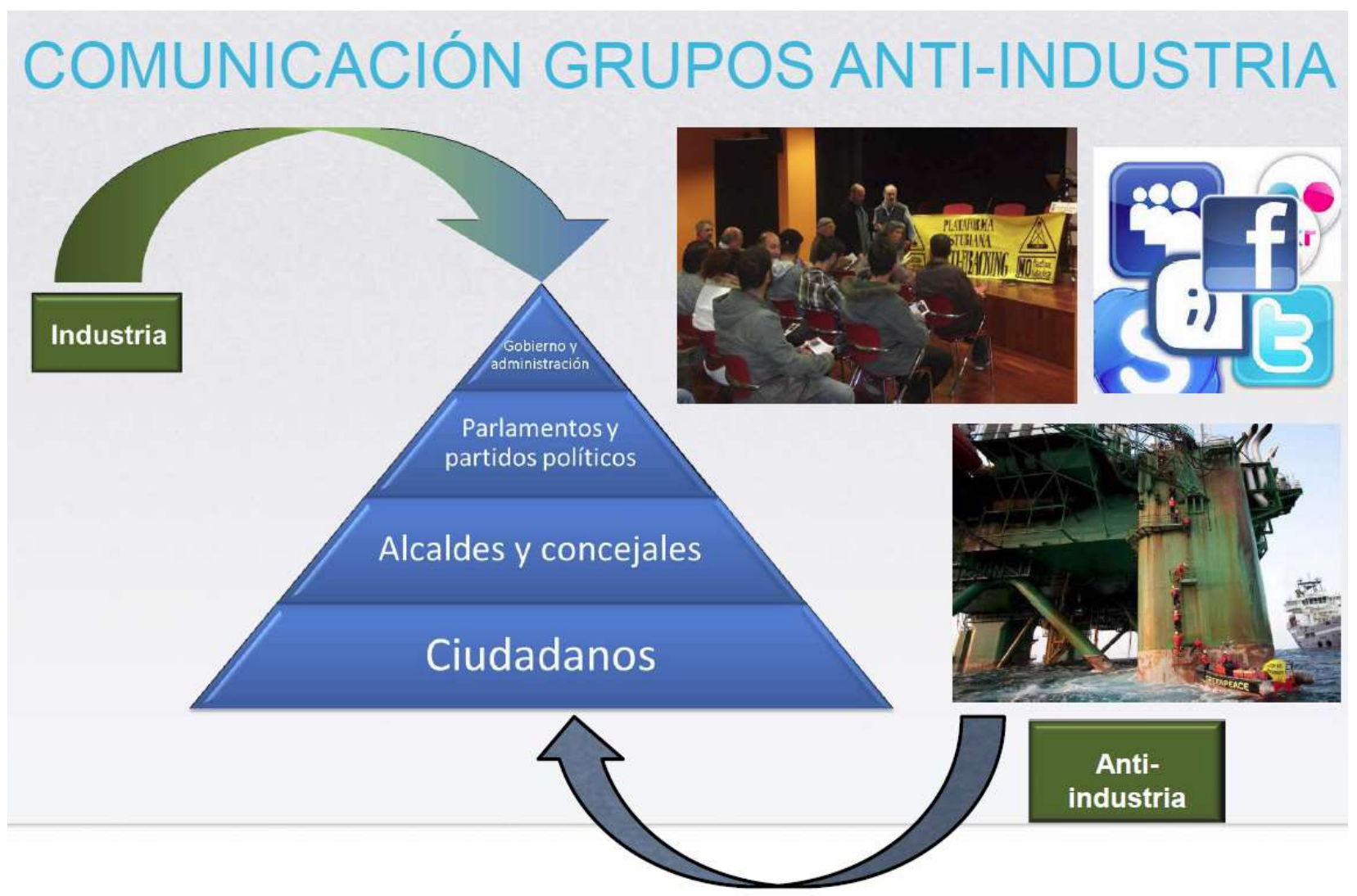

Figura 20. Pirámide de comunicación anti-industria. Fuente: Regueiro, M. (2015).

Figure 20. Anti-industry communication pyramid. Source: Regueiro, M. (2015). 
respecto al tema, así como múltiples opiniones que distan entre el apoyo incondicional al rechazo extremista.

Por un lado, algunos organismos como SHESA, $\mathrm{SGE}$, o ACIEP lo apoyan basándose en análisis y estudios detallados, algunos de ellos expuestos en este artículo. Otros organismos como el IGME, con múltiples estudios a su espalda, se muestran precavidos respecto al tema apoyando la necesidad de investigación sobre este tipo de recursos para conocer el potencial de nuestro país. Además, de ser posible un aprovechamiento de estos recursos, este último apuesta por una explotación sostenible con el medio ambiente, en riguroso cumplimiento de las estrictas medidas de seguridad de la legislación vigente. Por último, nos encontramos con los organismos opositores, representados principalmente por Greenpeace o plataformas antifracking, que exponen sus críticas en muchas ocasiones sin estudios precedentes, que terminan en las noticias o columnas de opinión de periódicos locales.

Esto sucede en muchas ocasiones por errores en el enfoque comunicativo. Muchas empresas, como ya admitió la propia ACIEP, trataron de convencer con sus técnicas de fracturación hidráulica a la administración y no a la población, y como puede verse en la Figura 20 este procedimiento no funciona. Antes de convencer al gobierno, hay que tratar de informar a los ciudadanos, ya que son estos últimos los que eligen a su gobierno, y no lo harán si no conocen qué es, como funciona y qué consecuencias tiene la fracturación hidráulica en el país (comunicación personal: Regueiro, M.).

En la Figura 21 pueden observarse multitud de noti-

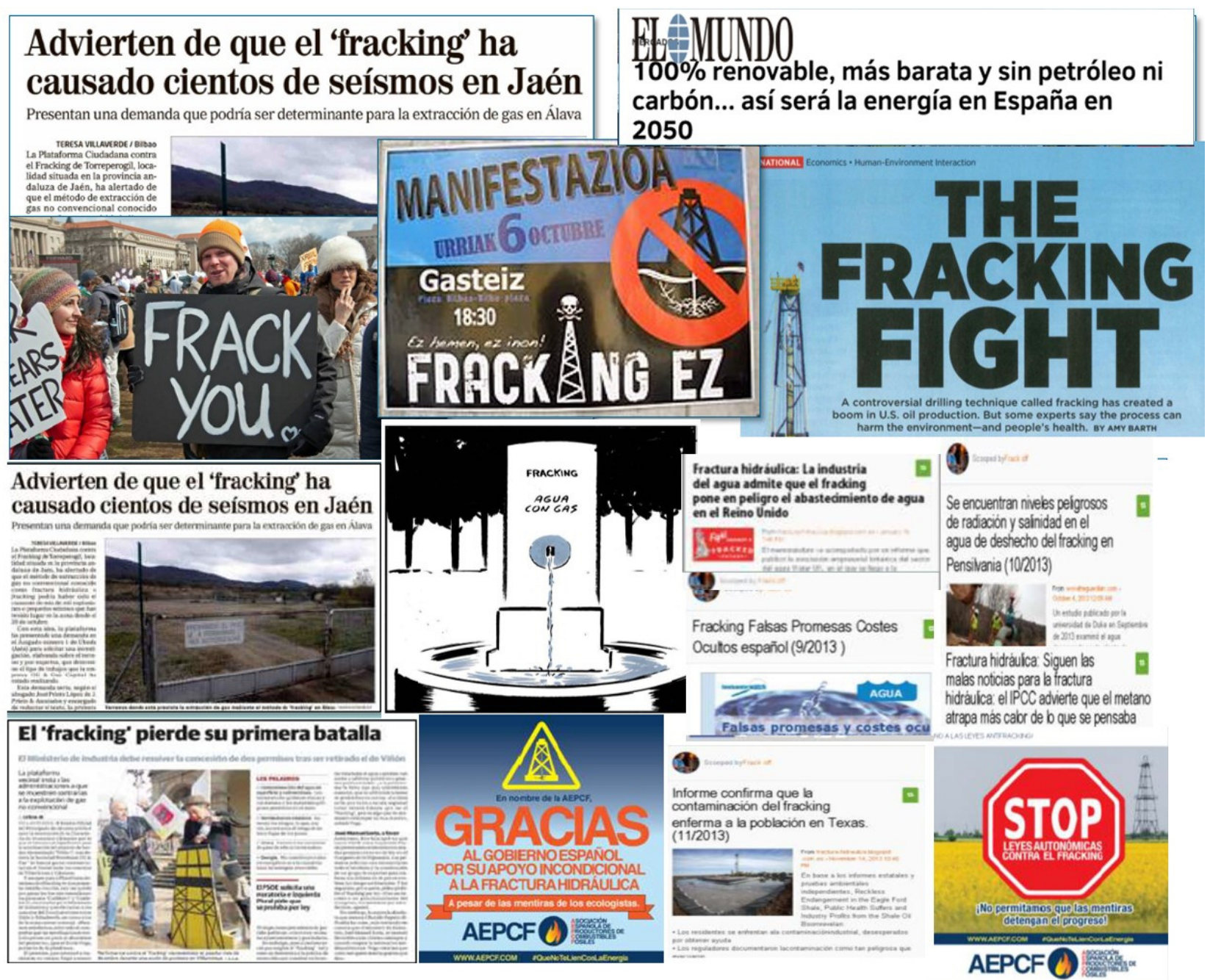

Figura 21. Noticias relacionadas con la fracturación hidráulica. Modificado de Regueiro, M., 2016 y Álvarez Fernández, I., 2017. Figure 21. News related to hydraulic fracturing. Modified by Regueiro, M., 2016 and Álvarez Fernández, I., 2017. 

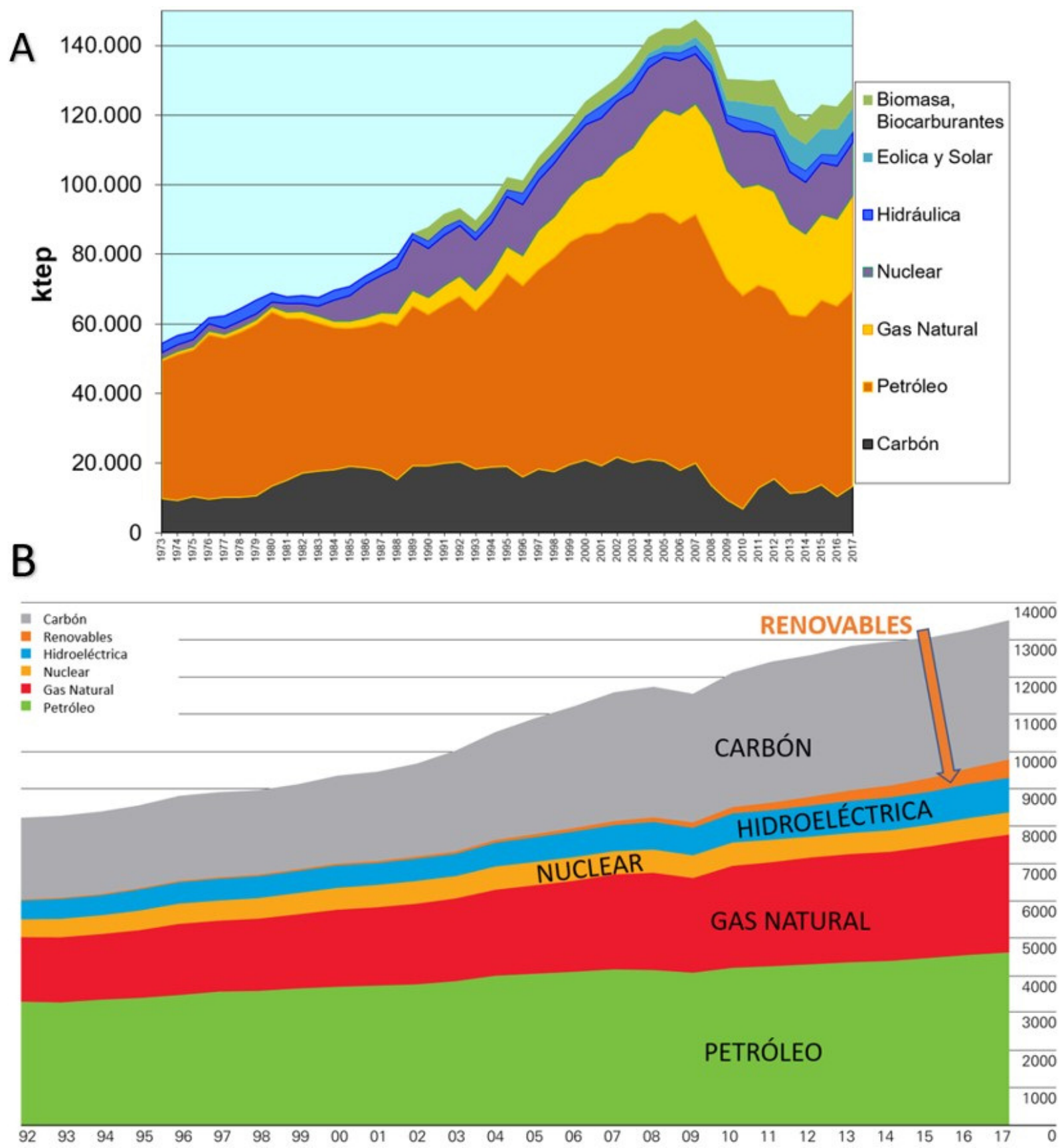

Figura 22. Consumo de energía primaria a nivel nacional (A) y a nivel mundial (B) a lo largo de los últimos años, en millones de toneladas equivalentes de petróleo. Fuente: BP Statistical Review of World Energy 2018.

Figure 22. Consumption of primary energy at the national level $(A)$ and worldwide $(B)$ over the last few years, in millions of equivalent tons of oil. Source: BP Statistical Review of World Energy 2018.

cias procedentes de webs y periódicos locales relacionadas con el tema. Especial atención reciben titulares como el que apareció en el periódico El Mundo, que decía así: "100\% renovable, más barata y sin petróleo ni carbón... así será la energía en España en 2050". En realidad, éste es un hecho prácticamente inalcanzable, ya que la energía renovable, si bien es cierto que tiene mucho futuro, también tiene una evolución muy lenta, y tal y como puede verse en el consumo de energía primaria a nivel nacional y mundial (Figura 22), cuesta creer que la energía renovable pueda suplir el resto de energías en los próximos 32 años. 
Otra noticia no exenta de polémica decía así: "Advierten que el fracking ha causado cientos de seísmos en Jaén". Y esto no pudo ser posible, ya que no se ha realizado técnica alguna de fracturación hidráulica para extracción de gas no convencional en el país; se han llegado a conceder varios permisos de exploración, pero ninguno de explotación. Además, posteriormente se ha visto que los sismos generados en la provincia jiennense de La Loma han sido provocados por dos fallas localizadas a $\mathbf{4 0 0 0}$ metros de profundidad, descartando así todo origen antrópico (Donaire, G; en línea).

\section{Conclusiones}

En un contexto de transitoriedad a energías con menor huella de carbono y a una electrificación del abastecimiento energético global como en el que nos encontramos, la entrada en escena de esta nueva fuente energética supone un papel crucial. Al menos, ésta parece ser la tendencia global a seguir hasta 2045, donde se prevé una reducción importante del empleo de petróleo como fuente energética. Gracias a este recurso no convencional, EEUU ha pasado de ser un neto importador a primer productor del mundo en petróleo y gas. Como consecuencia, cabe pensar que muchos países occidentales vayan a seguir su ejemplo.

España depende en un $99.8 \%$ de importaciones de gas, y sin embargo se estiman cantidades importantes de este recurso no convencional, y se cuenta con la tecnología y mecanismos de control para las operaciones de exploración y producción de gas no convencional.

A partir de toda la experiencia estadounidense, la técnica de fracturación hidráulica se ha convertido en una técnica muy madura que, acompañada de la estricta legislación medioambiental de la que disponemos, no debería suponer grandes riesgos; aunque no está exenta de complicaciones que han de ser observadas con minuciosidad y rigor.

El debate social en torno a la fracturación hidráulica se realiza sobre asertos basados en información no fidedigna, en lugar de estudios científicos reglados. Por ello se debe informar y ser transparente para conocer lo que supone el acceso a este recurso energético, sacando el debate de la calle y llevándolo al ámbito profesional, así como fomentar un interés por parte de los propietarios de los terrenos y municipios.

Teniendo todo esto en cuenta, no podemos planificar y resolver el futuro energético de nuestro país como si estuviéramos al margen del resto del mundo. Europa ya ha cometido un error en su planificación industrial y energética, y el resultado ha sido una pérdida en la competitividad y un aumento de los precios de la energía que mes a mes acaba reflejándose en la factura energética, disminuyendo así el nivel de vida de los europeos y poniendo trabas a su sector industrial, haciéndolo menos competitivo.

Por tanto, para formar parte del cambio, hay que comenzar permitiendo la investigación y exploración de hidrocarburos no convencionales en España. Así podría realizarse una correcta y minuciosa evaluación de los recursos de los que disponemos, así como un riguroso estudio del modo que habría que emplear para extraerlos, afectando con el menor impacto posible a nuestra salud y entorno. De esta forma, se deberá considerar si es o no viable llevar a cabo la explotación de recursos no convencionales en el país.

Hoy en día todo proyecto de exploración de recursos no convencionales en España se encuentra congelado. No obstante, el recurso sigue ahí, y puede que llegue el momento en el que resulte de interés.

\section{Referencias}

Advanced Resources International, Inc. (ARI) (2013) World Shale Gas and Shale Oil Resource Assessment. Report for U.S. Energy Information Administration (EIA) and U.S. Department of Energy.

Alameda, D. 2014. "El gas no convencional". Jornada técnica ACEFER. Shale Gas España. Plataforma española sobre la exploración y desarrollo del shale gas. www.shalegasespana.es

Álvarez Fernández, I. 2017. ¿Qué sabes de los Hidrocarburos? Aspectos ambientales de los hidrocarburos no convencionales. Ciclo de conferencias. Asociación Española de Compañías de Investigación, Exploración y Producción de Hidrocarburos y Almacenamiento Subterráneo (ACIEP). Instituto Geológico y Minero de España. Madrid.

Álvarez, E., y Suárez, C. 2016. Gas no convencional: shale gas. Aspectos estratégicos, técnicos, medioambientales $y$ regulatorios. Orkestra. Instituto Vasco de Competividad. Fundación Deusto. Ediciones Jurídicas y Sociales, S.A. ISBN: 978-84-16402-94-6. Madrid

Álvarez, I., 2015. La Exploración y Producción de Hidrocarburos del Siglo XXI: El Fracking - ¿Una revolución? Ciclo de conferencias. Escuela Técnica superior de Ingenieros de Minas y Energía de Madrid. Fundación Gómez Pardo. Fundación Repsol. Madrid.

Arenillas, A. 2014. Shale gas y la técnica del fracking. Instituto Geológico y Minero de España. Ciclo de conferencias ST-3. Fundación Conama.

Beroiz, C. and Permanyer, A. 2011. Hydrocarbon habitat of the Sedano trough, Basque-Cantabrian basin, Spain. Journal of Petroleum Geology, 34(4), 387-409.

Boletín Oficial del Estado. Gobierno de España. Real Decreto 316/2013, de 26 de abril, por el que se otorga a Frontera Energy Corporation, S.L., el permiso de inves- 
tigación de hidrocarburos denominado "Aquiles" (en línea). https://www.boe.es/diario_boe/txt.php?id=BOEA-2013-5039 [accessed 18/10/2017].

BP Stadistical Review of World Energy 2018. Edición 67.

Cámara Rascón, A. and Pendas Fernández, F; 2013. Gas no Convencional en España, una Oportunidad de Futuro. Informe del Consejo Superior de Colegios de Ingenieros de Minas.

Cámara, P. 2015. Geología y sistemas petroleros de la Cuenca Vasco-Cantábrica. Universidad Complutense de Madrid, España.

Cayola Cortés, F. J. 2014. Shale Gas y la Técnica del Fracking: Requerimientos administrativos. Fundación Conama. Ministerio de Industria, Energía y turismo.

Confuzal - Derechos sobre los minerales de tierras (en línea). http://confuzal.com/articulo/Derechos\%20sobre $\% 201$ os $\% 20$ minerales $\% 20$ de $\% 20$ tierras $\% 20 /$ [accessed 22/09/2017].

Curbelo, J.L, et al, 2012. Gas no convencional: shale gas Orkestra. Instituto Vasco de Competividad. Fundación Deusto. Publicaciones de la Universidad de Deusto. ISBN: 978-84-9830-414-5.

Donaire, G. 2013. Los terremotos de La Loma se producen por dos fallas localizadas en el subsuelo [en línea]. El País. Madrid. <https://elpais.com/ccaa/2013/11/07/andalucia/1383857515_500586.html> [Consulta: 15/05/2016].

Drillinginfo - Approach Does A Great Job Explaining The Wolffork In Crockett County (en línea). DI Blog «Engineering, Geology, Operators, Permian». https://info.drillinginfo.com/approach-does-a-great-jobexplaining-the-wolffork-in-crockett-county/ [accessed 13/10/2017].

Earthworks. La acidificación (en línea). Earthworks "lssues». https://earthworks.org/issues/la_acidificacion/ [accessed 19/09/2017].

El Financiero. Tech. Elon Musk quiere alimentar de energía con paneles solares a todo EU (en línea). http://www.elfinanciero.com.mx/tech/elon-musk-quiere-alimentar-deenergia-con-paneles-solares-a-todo-eu.html [accessed 17/10/2017].

Elzafrany, B., 2016. Unconventional reservoirs Supervised by Dr Abdel Moktader A. El Sayed.

Energía estratégica. El cambio de paradigma energético es necesario pero difícil (en línea). Energía estratégica. https://www.energiaestrategica.com/opinion-cambioparadigma-energetico-necesario-e-inevitable-dificil/ [accessed 16/10/2017].

Escribano, S; 2018. Los desistimientos de las petroleras dan sepultura oficial a los permisos de fracking (en línea). El Norte de Castilla. https://www.elnortedecastilla.es/castiIlayleon/desistimientos-petroleras-sepultura20181118191730-nt.html [accesed 08/05/2019].

Estefanell Alós, J., 2014. Estudio de rentabilidad del shale gas en Europa: Cuenca Bowland-Hodder, Reino Unido. Proyecto final de carrera. Departamento de Ingeniería Química y Combustibles. Escuela Técnica Superior de Ingenieros de Minas, Madrid.

Foro de la Industria Nuclear Española, 2017. Energía 2017 (en línea). Madrid. www.foronuclear.org [accesed 3/07/2018].
García Portero, J., 2013. Hidrocarburos no convencionales (I). Tierra y Tecnología; 41. Ilustre Colegio Oficial de Geólogos.

García Portero, J., 2013. Hidrocarburos no convencionales (II). Tierra y Tecnología; 42. Ilustre Colegio Oficial de Geólogos.

García Portero, J., 2015. Hidrocarburos no convencionales. Situación actual. Tierra y Tecnología; 45.

García-Pérez, A. et al 2018. Estado del conocimiento en la explotación del Gas de Lutita (Shale Gas) y su potencial geológico en el Norte de España. Boletín de la Real Sociedad Española de Historia Natural 112. Sección Geológica.

GESSAL. 2013. Evaluación preliminar de los recursos prospectivos de hidrocarburos convencionales y no convencionales en España. Asociación Española de Compañías de Investigación, Exploración, Producción y Almacenamiento de Hidrocarburos (ACIEP).

Gil Villamer, P. L. 2015. Plataformas petrolíferas y procesos para la extracción del petróleo. Trabajo de Fin de Grado. Escuela Politécnica Superior de Ingeniería. Universidad de La Laguna.

IGME. 2014. Recomendaciones ambientales en relación con las medidas preventivas y correctoras a considerar en proyectos relacionados con la exploración y explotación de hidrocarburos mediante técnicas de fractura hidráulica. Guía de Gestión de la Dirección General de Calidad, Evaluación Ambiental y Medio Natural. Instituto Geológico y Minero de España. Ministerio de Agricultura, Alimentación y Medio Ambiente. Madrid.

Izquierdo Llanes, G. 2017. España en Cifras 2017. Instituto Nacional de Estadística. www.ine.es

Martínez Abad, I. 2007. Geología del área situada entre Peña Ubiña y el puerto de La Cubilla (Zona Central de la Cordillera Cantábrica). Tesis de Máster Oficial en Recursos Geológicos y Geotecnia. Facultad de Geología. Universidad de Oviedo.

Martínez Orio, R., et al. 2014. Estudio de las áreas con potencial de Shale Gas en el principado de Asturias. Proyecto: Realización de un estudio hidrogeológico en estructuras geológicas relevantes y con potencial actividad económica. Instituto Geológico y Minero de España. Ministerio de Economía y Competitividad. Madrid.

Milno, S. Fracking with propane gel (en línea). Chemistry World. https://www.chemistryworld.com/news/frackingwith-propane-gel/3001695.article [accesed 27/10/2017].

Planelles, M., 2015. La canadiense BNK pide emplear el fracking en 12 pozos de Burgos (en línea). El País "Fracturación hidráulica». https://elpais.com/politica/2015/02/18/actualidad/1424259558_413026.html [accesed 7/06/2019].

Planelles, M., 2017. La burbuja del fracking en España se pincha (en línea). El País "Medioambiente». http://politica.elpais.com/politica/2017/03/12/actualidad/ 1489327921_945088.html [accesed 16/05/2016].

Planelles, M; 2016. El Congreso insta al Gobierno a cerrar la puerta al 'fracking' en España (en línea). El País "Fracturación hidráulica». https://elpais.com/politica/2016/03/29/actualidad/1459243511_148398.html [accesed $6 / 06 / 2019]$ 
Planelles, M; 2016. La canadiense BNK renuncia a uno de sus proyectos de 'fracking' en Burgos (en línea). El País "Fracturación hidráulica». ttps://elpais.com/politica/2016/06/02/actualidad/1464868092_144919.html [accesed 6/06/2019].

Prieto, J. 2014. Gas no convencional en España y potenciales implicaciones en el medio hídrico subterráneo. Facultad de Ciencias Geológicas. Universidad Complutense de Madrid. Prácticas profesionales, Instituto Geológico y Minero de España, Madrid.

Regueiro, M. 2016. La Fracturación Hidráulica. Ilustre Colegio Oficial de Geólogos de España. Federación Europea de Geólogos.

Scheyder, E. Fracking with $\mathrm{CO}_{2}$ to replace water a distant goal, GE says (en línea). Reuters "Market news». https://www.reuters.com/article/generalelectric-frackingcarbon/fracking-with-co2-to-replace-water-a-distantgoal-ge-says-idUSL1N0MT1HN20140407 [accessed 27/ 10/2017].

Secretaría de Estado de Energía. Mapa de posición de sondeos, permisos y concesiones (en línea). Ministerio de energía, turismo y agenda digital. Gobierno de España "Mapa del año 2018». www.minetad.gob.es [accessed 25/05/2019].

Serrano González, M. 2015. La Regulación del Gas no convencional ("Fracking") en España. Informe Estratégico de la Fundación para la Sostenibilidad Energética y Ambiental. Funseam - Fundación para la Sostenibilidad Energética y Ambiental.

Sieminski, A. 2017. Annual energy outlook 2017. AEO2017 Rollout Presentation. US Energy Information
Administration. Johns Hopkins School of Advanced International Studies, Washington, D.C.

U.S Energy Information Administration. Analysis \& projections (en línea). World Shale Resource Assessments. https://www.eia.gov/analysis/studies/worldshalegas/ [accessed 15/09/2017].

U.S Energy Information Administration. Maps: Exploration, Resources, Reserves, and Production (en línea). U.S Energy Information Administration "Maps». https://www.eia.gov/maps/maps.htm\#shaleplay [accessed 15/09/2017].

US DPT OF ENERGY. 2015. Technically Recoverable Shale Oil and Shale Gas Resources: Spain. U.S Energy Information Administration. US Department of Energy, Washington, DC.

Valencia Plaza. Aprobado el anteproyecto de Ley de Cambio Climático para que España sea neutra en $\mathrm{CO}_{2}$ en 2050 (en línea). https://valenciaplaza.com/aprobado-el-anteproyecto-de-ley-de-cambio-climatico-para-que-espanasea-neutra-en-co2-en-2050 [accesed 10/06/2019].

Verdon J.P. Frack-Land, Exploring the development of hydraulic fracturing in the UK (en línea). http://frackland.blogspot.com.es/2014/11/image-of-day-reclaimedwell-pads.html [accessed 27/10/2017].

Wang, Z. and Krupnick, A. 2013. A retrospective review of shale gas development in the United States: What led to the boom? Symposium on "Shale Gas". Washington, DC. Economics of Energy \& Environmental Policy 4(1), 517.

Wigley, T. M. 2011. Coal to gas: the influence of methane leakage. Climatic Change 108(3), 601-608.

Recibido: julio 2018

Revisado: septiembre 2018

Aceptado: mayo 2019

Publicado: septiembre 2019 
